\title{
A Sensitivity Analysis of the Anisotropy of Hydraulic Conductivity to the Seepage, Deformation and Stability of Anti-Dipping Layered Rock Slopes: A Case Study of the Pulang Area in Southwestern China
}

\section{Guangkeng Zhang}

Central South University

Guangyin Lu ( $\square$ luguangyin@csu.edu.cn )

Central South University

Chengzhi Xia

Central South University

Lianrong Wu

Central South University

Zongming $\mathrm{Xu}$

Central South University

Ying Bai

Central South University

Jialu Li

Central South University

\section{Original Paper}

Keywords: anisotropy of hydraulic conductivity, anti-dipping layered rock slopes, anisotropy ratios, anisotropy angles, numerical simulations

Posted Date: February 9th, 2021

DOl: https://doi.org/10.21203/rs.3.rs-172431/v1

License: (c) (1) This work is licensed under a Creative Commons Attribution 4.0 International License. Read Full License 



\title{
1 Geotechnical and Geological Engineering
}

\section{A Sensitivity Analysis of the Anisotropy of Hydraulic}

3 Conductivity to the Seepage, Deformation and Stability of Anti-

4 Dipping Layered Rock Slopes: A Case Study of the Pulang Area

\section{in Southwestern China}

6

\author{
Guangkeng Zhang ${ }^{1,2,3} \cdot$ Guangyin $\mathrm{Lu}^{1,2,3} \cdot$ Chengzhi Xia ${ }^{1,2,3} \cdot$ Lianrong $\mathrm{Wu}^{4} \cdot$ Zongming $\mathrm{Xu}^{5} \cdot$ Ying \\ $\mathrm{Bai}^{5} \cdot \mathrm{Jialu} \mathrm{Li}^{2,3}$ \\ ${ }^{1}$ School of Geosciences and Info-Physics, Central South University, Changsha 410083, China; \\ zgk2019@csu.edu.cn (Guangkeng Zhang); xiachengzhi@csu.edu.cn (Chengzhi Xia) \\ ${ }^{2}$ Key Laboratory of Metallogenic Prediction of Nonferrous Metals and Geological Environment Monitoring \\ Ministry of Education, Central South University, Changsha 410083, China; dj195011068@csu.edu.cn (Jialu Li) \\ ${ }^{3}$ Hunan Key Laboratory of Nonferrous Resources and Geological Hazards Explortion, Changsha 410083, China \\ ${ }^{4}$ Yunn Diqing Nonferrous Metals Co., Ltd., Diqing 474400, China; keliang_shi@ @csu.edu.cn (Lianrong Wu) \\ ${ }^{5}$ China Nonferrous Metals Industry Kunming Survey, Design and Research Institute Co., Ltd. Experimental \\ Center, Kunming 650000, China; 195011071@ @ csu.edu.cn (Zongming Xu); 0110160309@csu.edu.cn (Ying Bai)
}

Correspondence should be addressed to Guangyin Lu; luguangyin@csu.edu.cn

\begin{abstract}
In this paper, in order to study the influencing effects of anisotropy ratios and anisotropy directions on the seepage, deformations and stability of the anti-dipping layered rock slopes, Geo-studio software was used in this study to carry out this test based on the unsaturated seepage, fluid-solid coupling, and stability theory numerical analysis of carbonaceous slate slopes in Pulang area. The results showed that the maximum surface water content of the layered rock slopes gradually decreased with increases of the water conductivity anisotropy ratio and decreases in the anisotropy angle of the anti-dipping layered rock slopes. In addition, the rainfall infiltration depths in the middle sections of the slopes were observed to be the most affected by the anisotropy ratio and dip angles of the rock formations. Meanwhile, the bottom sections of slopes were the least affected by the anisotropy ratio and the dip angles of the rock formations. In regard to the anti-dipping rock slopes, it was found that the anisotropy ratio and rock layer dip angles should be considered in the deformation and stability analyses. When the seepage of an anti-dipping layered slope was considered to be isotropic, the safety factors often were overestimated. As the anisotropy ratio decreases and the anti-tilt angles of the layered planes increases, the safety factors of the slopes will gradually decrease. This study provided a feasible scheme for evaluating the seepage, deformations and stability of the anti-dipping layered rock slopes in southwest China's Pulang area.
\end{abstract}

Keywords: anisotropy of hydraulic conductivity · anti-dipping layered rock slopes · anisotropy ratios · anisotropy angles $\cdot$ numerical simulations

\section{Introduction}

In addition to earthquakes and volcanic eruptions, landslides are one of the three major global geological disasters. Landslides caused by slope instability have always been important subjects in geotechnical engineering. As shown in Table 1, some of China's major landslide events have resulted in significant economic losses. There are many factors which are known to cause landslides, such as heavy rainfall, earthquakes, and reservoir storage processes (Iverson 2000; Zhong et al. 2007). In recent years, more than $80 \%$ of China's landslide disasters occurred in the months of May to September when rainfall was abundant, with more than $90 \%$ of the landslides induced by heavy rainfall (Zhang et al. 2005). The main reasons for the landslides caused by rainfall are as follows: (1) Rainfall reduces the matrix suction of rock slopes, thereby reducing the effective stress and shear strength of 
rock masses; (2) Heavy rainfall increases the horizontal displacements of slopes and aggravates the instability of the slopes. Rainfall-induced landslides have posed severe threats to China, as well as other countries throughout the world, by severely restricting the economic development of landslide disaster areas and threatening the lives and property of the majority of people in those affected regions. For example, in August of 2013, southern China underwent heavy rains, and landslides occurred along the railway system from Chenzhou, Hunan to Shaoguan, Guangdong. The railway transportation system was severely blocked, causing about 20,000 passengers to be stranded at the Guangzhou Railway Station. In July of 2019, an extremely large landslide occurred in the Chagou Group of Pingdi Village, located in Jicang Town, Shuicheng County, Liupanshui City, Guizhou Province. The disaster resulted in the deaths of 51 people. The data monitored by the Meteorological Department showed that the incident was concentrated in the region which had experienced recent heavy rainfall (Liu et al. 2010). From the above-mentioned examples, it can be seen that slope instability damages are closely related to heavy rainfall events. Therefore, deepening the understanding the mechanism of rainfall infiltration will potentially be of major significance in future measures implemented for the prevention and control of landslide disasters.

Table 1 Landslide disasters in China recent years

\begin{tabular}{ccc}
\hline Landslide site & The number of casualties & Property loss \\
\hline Shenzhen Guangming & 77 people were killed & 880 million yuan \\
Shanyang County & 65 people were killed & 500 million yuan \\
Tibet Yigong & 96 people were killed & 420 million yuan \\
Ganjiangping & 24 people were killed & 57.35 million yuan \\
Sichuan Wangjiayan & 1,700 people were killed & 16 million yuan \\
Guizhou Shuicheng & 52 people were killed & 190 million yuan \\
\hline
\end{tabular}

At the present time, the numerical simulations of rainfall-induced landslides are a hot issues. Many researchers have conducted studies regarding the mechanisms of rainfall infiltration. A large number of conceptual infiltration models and numerical simulations have been applied in order to examine rainfall-induced landslides. Based on Darcy's Law and rainwater infiltration quality conservation equations, Zhang Jie et al. (2014) established an infiltration layering hypothesis based on the change characteristics of loess infiltration profiles. Subsequently, the relationships between the infiltration depths and the time factors were derived, which were used to calculate the slope safety factors. Gan Yongde et al. (2015) introduced saturation coefficients for the purpose of quantifying the influencing effects of air resistance and established a Green-Ampt Model which considered the effects of air resistance under unsteady rainfall conditions. In terms of numerical simulations, Yang Pan and Yang Jun (2015) used the geotechnical finite element software Plaxis to consider rainfall infiltration and the properties of unsaturated soils, and then studied and analyzed landslide early warning rainfall thresholds. Some researchs, such as Kulatilake (2001), Zhou Weiyuan (1990), Yang (1998), Zhu Weishen (1994) and so on constructed rock mass models and numerical models using gypsum, yellow sand and other materials, for the purpose of investigating the anisotropic modes and seepage characteristics of rock masses.

However, this study observed that the majority of the previous related studies had regarded slope materials as isotropic materials. Song et al. (2018) conducted experiments regarding clay layers along horizontal and vertical directions in order to study the permeability coefficient and anisotropy of the shallow clay in Shanghai. The results revealed that the flocculent microstructures formed by sedimentation displayed large differences in the vertical and horizontal permeability coefficients. Lee (2020) conducted penetration experiments on sedimentary rock and determined that the ratio of the parallel/perpendicular to the bedding plane was 10-100. Ning Shuai et al. (2021) considered the anisotropy in slope stability analyses and found that when considering the anisotropy condition, the anisotropy was generally less than the safety factors under isotropic conditions. However, none of the abovementioned studies considered the anisotropy angles of hydraulic conductivity. Yu et al. (2020) performed numerical simulations of the permeability and stability of sandy clay. The results indicated that only under special circumstances, the horizontal permeability coefficient and the vertical permeability coefficient coincide with the natural coordinate axis. It has been observed that the anisotropy direction does not coincide with the coordinate axis in most situations. In recent years, researchs in the field have paid increasing amounts of attention to antidipping slopes. Su et al. (2012) established a typical anti-dipping rock slope model using the FINAL system and studied the failure mechanisms of this type of rock slope with different bedding dip angles. Yao Ye et al. (2020) studied the mechanisms of the deformations and failures of anti-dipping cataclastic structure rock slopes in southwestern China using various experimental processes and successfully obtained the failure mechanisms of anti-dipping layered rock slopes. Cheng et al. (2019) revealed the impacts of steep anti-dipping sandstone in mudstone slopes. Zhu et al. (2020) found that the failure mechanisms of anti-dipping layered slopes were essentially different from those of bedding slopes. Huang et al. [20] proposed a stability evaluation method for 
anti-dipping rock slopes and revealed the failure characteristics of landslides under different inclination angles. Tao et al. (2020) determined the failure modes of the Changshanhao gold mine slopes using field experiments and put forward suggestions for the reinforcement and treatment of dangerous slopes. Liu et al. (2020) selected the Diaokanlong Tunnel of the Rucheng-Chenzhou Expressway in central China as an example and analysed the deformation characteristics and evolution processes of the anti-dipping slope failure through field investigation, deformation monitoring and numerical analysis. However, the current research studies regarding anti-dipping layered rock slopes have focused on the failure mechanisms and there have been few studies completed regarding the seepage characteristics, deformations and stability levels of anti-dipping rock slopes.

In view of the shortcomings of the previous studies, this research investigation first described the mathematical definition of the anisotropy ratio and direction of hydraulic conductivity. Taking the strongly weathered anti-dipping layered rock slopes in the Pulang area of Yunnan, China as an example, the unsaturated seepage simulation was realized by the Van Genuchten and fluid-soild coupling theory. Then, the layered rock body water retention curves were obtained and a reasonable initial matrix suction was successfully determined. Finally, according to the volumetric water content, maximum surface water content (MWCS); rainfall infiltration depth (RID); maximum horizontal displacement (MHD) and the safety factor (SF) of three typical anti-incline slopes (top, middle and bottom), the effects of different anisotropy ratios and anisotropy angles on the permeability sensitivity, deformations and stability levels of anti-dipping layered rock slopes were discussed. The feasibility of this study's numerical simulations were confirmed using the field survey data. The research results provided important references for deepening understanding of anisotropy of hydraulic conductivity and landslide prevention.

\section{Methods and Theory}

\subsection{Control differential equation}

In this study, the SWEEP/W module in Geo-studio was used to simulate the seepage processes of the slopes. The rainfall infiltration vales were used as the variable flow boundaries of the unsaturated zones for the numerical simulations. According to the principle of conservation of mass, the saturated-unsaturated seepage control equation (SEEP/W 2007) was as follows:

$$
\frac{\partial}{\partial x}\left(k_{x} \frac{\partial H}{\partial x}\right)+\frac{\partial}{\partial y}\left(k_{y} \frac{\partial H}{\partial y}\right)+Q=m_{w} \gamma_{w} \frac{\partial H}{\partial t}
$$

Where $x$ and $y$ are the coordinates in the direction of $x$ and $y ; \mathrm{H}$ is the total head, and the unit is $\mathrm{m} ; k_{x}$ represents the hydraulic conductivity in the $\mathrm{x}$-direction, and the unit is $\mathrm{m} / \mathrm{s} ; k_{y}$ indicates the hydraulic conductivity in the $\mathrm{y}$ direction, and the unit is $\mathrm{m} / \mathrm{s}$; Q represents the applied boundary flux, in which $m_{w}$ is the slope of the storage curve; $t$ is the time, and the unit is s; $\gamma_{w}$ denotes the unit weight of the water, and the unit is $\mathrm{N} / \mathrm{m}^{3}$.

\subsection{Fluid-structure interactions}

In this study, when solving the rock and soil deformations of slopes, a fluid-structure interaction theory was adopted. Meanwhile, the seepage and rock and soil deformations were solved simultaneously. The finite element equilibrium equation could then be expressed by the virtual work principle in the Geo-studio SIGMA / W system, which indicated that the total internal virtual work was equal to the external virtual work. In simple cases, when only the external point load $\{F\}$ is applied, the virtual work equation can be written as follows:

$$
\int\left\{\varepsilon^{*}\right\}^{T}\{\Delta \sigma\} d V=\int\left\{\delta^{*}\right\}^{T}\{F\} d V
$$

Where $\left\{\delta^{*}\right\}$ indicates the virtual displacement; $\left\{\varepsilon^{*}\right\}$ denotes the virtual strain; and $\{\sigma\}$ is the internal stress. Therefore, the two-dimensional seepage flowing through a unit of soil can be expressed by the Darcy Equation as follows:

$$
\frac{k_{x}}{y_{w}} \frac{\partial^{2} u_{w}}{\partial x^{2}}+\frac{k_{y}}{y_{w}} \frac{\partial^{2} u_{w}}{\partial y^{2}}+\frac{\partial \theta_{w}}{\partial t}=0
$$

Where $k_{x}$ and $k_{y}$ represent the hydraulic conduction coefficients in the $x$ and $y$ directions, respectively; $u_{w}$ is the seepage velocity; $y_{w}$ indicates the unit weight of the water; $\theta_{w}$ is the volumetric water content; and $t$ denotes the 
(Dakshanamurthy and Rahardjo 1984):

$$
\left.\begin{array}{r}
\beta=\frac{E}{H} \frac{1}{(1-2 v)}=\frac{3 K_{B}}{H} \\
\omega=\frac{1}{R}-\frac{3 \beta}{H}
\end{array}\right\}
$$

139 Where $K_{B}$ indicates the bulk modulus; and $R$ is the modulus related to volumetric water content as a function of 140 the matrix suction. Then, by inputting equation (3) into equation (2), numerical integration can be performed. The 141 finite element equation solved by SIGMA / W can then be expressed by the following equations:

$$
\sum[B]^{T}[D][B]\{\Delta \delta\}+\sum[B]^{T}[D][B]\left\{m_{H}\right\}\langle N\rangle\left\{\Delta u_{w}\right\}=\sum F
$$

$$
[K]=[B]^{T}[D][B]
$$

$$
\left[L_{d}\right]=[B]^{T}[D]\left\{m_{H}\right\}\langle N\rangle
$$

$$
\left\{m_{H}\right\}^{T}=\left\langle\frac{1}{H} \frac{1}{H} \frac{1}{H} 0\right\rangle
$$

Where $[B]$ represents the gradient matrix; $[D]$ is the constitutive matrix for the drainage; $[K]$ indicates the stiffness matrix; $\left[L_{D}\right]$ denotes the coupling matrix; $\{\Delta \delta\}$ is the incremental displacement vector; and $\Delta u_{w}$ represents the incremental pore water pressure (PWP) vector.

\subsection{Safety factors of unsaturated layered rock slopes}

In this study, the Morgenstern-Price Method, which is based on a limit equilibrium theory was used to calculate the safety factors of the slopes. The aforementioned method has the ability determine the relevant parameters more accurately by studying the sliding surfaces of rock landslides under the limit equilibrium state, thereby providing a reliable basis for the analysis and design of landslide engineering (Morgenstern and Price 1965). Therefore, it was considered to be reasonable to use the Morgenstern-Price Method for this study's slope stability analysis (Xiao and $\mathrm{Li} 2020$ ). In addition, the improved method satisfied both the force balance and torque balance requirements, and the calculation accuracy was observed to be higher.

This study selects a rock slice as the research object, as shown in Fig. 1. According to the balance of the force in the normal and tangential directions of the slip surfaces of the rock slice, when the boundary conditions were $E_{0}=0$ and $E_{n}=0$, the following was obtained:

$$
S_{i}=\left(N_{i} \tan \varphi+c b \sec \alpha\right) / F_{S}
$$

$$
\left.N_{i}=\left(W_{i}+\lambda f_{i-1} E_{i-1}-\lambda f_{i} E_{i}+Q_{i} \cos w_{i}+J_{i} \sin \beta_{i}\right) \cos \alpha+E_{i}-E_{i-1}+Q_{i} \sin \omega_{i}-J_{i} \cos \beta_{i}\right) \sin \alpha_{i}
$$

162 Where $N_{i}$ is the effective normal force on the slip surfaces of the rock slice and the unit is $\mathrm{kN} ; S_{i}$ indicates the 163 shear force on the slip surfaces of the rock slice and the unit is $\mathrm{kN}$ and the safety factor $F s$ can be derived as 164 follows:

$$
F s=\frac{\sum_{i=1}^{n-1}\left(R_{i} \prod_{j=i}^{n-1} \psi_{j}\right)+R_{n}}{\sum_{i=1}^{n-1}\left(T_{i} \prod_{j=i}^{n-1} \psi_{j}\right)+T_{n}}
$$

166 Where $R_{i}$ is the resistance force, $R_{i}=\left[W_{i} \cos \alpha_{i}+Q_{i} \cos \left(\omega_{i}-\alpha_{i}\right)+J_{i} \sin \left(\beta_{i}-\alpha_{i}\right)\right] \tan \varphi_{i}+c_{i} b_{i} \sec \alpha_{i}$ and the unit 167 is $\mathrm{kPa} ; T_{i}$ is the sliding force, $T_{i}=W_{i} \sin \alpha-Q_{i} \sin \left(\omega_{i}-\alpha_{i}\right)+J_{i} \cos \left(\beta_{i}-\alpha_{i}\right) ; \psi_{i}$ denoets the transfer coefficient, 
$\psi_{i-1}=\frac{\left(\sin \alpha_{i}-\lambda f_{i-1} \cos \alpha_{i}\right) \tan \varphi_{i}+\left(\cos \alpha_{i}+\lambda f_{i-1} \sin \alpha_{i}\right) F s}{\left(\sin \alpha_{i-1}-\lambda f_{i-1} \cos \alpha_{i-1}\right) \tan \varphi_{i-1}+\left(\cos \alpha_{i-1}+\lambda f_{i-1} \sin \alpha_{i-1}\right) F s} ; c_{i}$ represents the effective cohesion for every rock slice and the unit is $\mathrm{kPa} ; \varphi_{i}$ represents the shear strength angle for every rock slice, and the unit is the degree; $J_{i}$ is the seepage force of the rock slippage which adopts a simplified seepage field treatment method, assuming that its position of action is located at the center of the gravity of the rock below the underwater line, and the distance from the center of the slip surface of the rock strip is $h_{w i} / 2 ; h_{w i}$ denotes the distance from the underwater line to the slip surface; $E_{i}$ and $E_{i-1}$ are the horizontal effective forces between the two sides of the rock slices and the unit is $\mathrm{kN} ; \lambda f_{i} E_{i}$ and $\lambda f_{i-1} E_{i-1}$ represent the shear forces between the two sides of the rock strip; $f_{i}$ is the function of the inter-strip force; and $\lambda$ is the proportional coefficient. The distances between the action positions on both sides and the center of the slip surfaces of the rock strip are denotes as $Z_{i}$ and $Z_{i-1}$, respectively; $W_{i}$ is divided into two parts based on the underwater line: $W_{i}=W_{i 1}+W_{i 2}$, where $W_{i}$ is the gravity of the rock above the underwater line and $W_{i 2}$ represents the floating weight of the rock below the underwater line; $Q_{i}$ indicates the external force on the rock surface; $\omega_{i}$ is the angle between the direction of the external force and the normal direction; $\alpha_{i}$ indicates the angle of the slip surface.

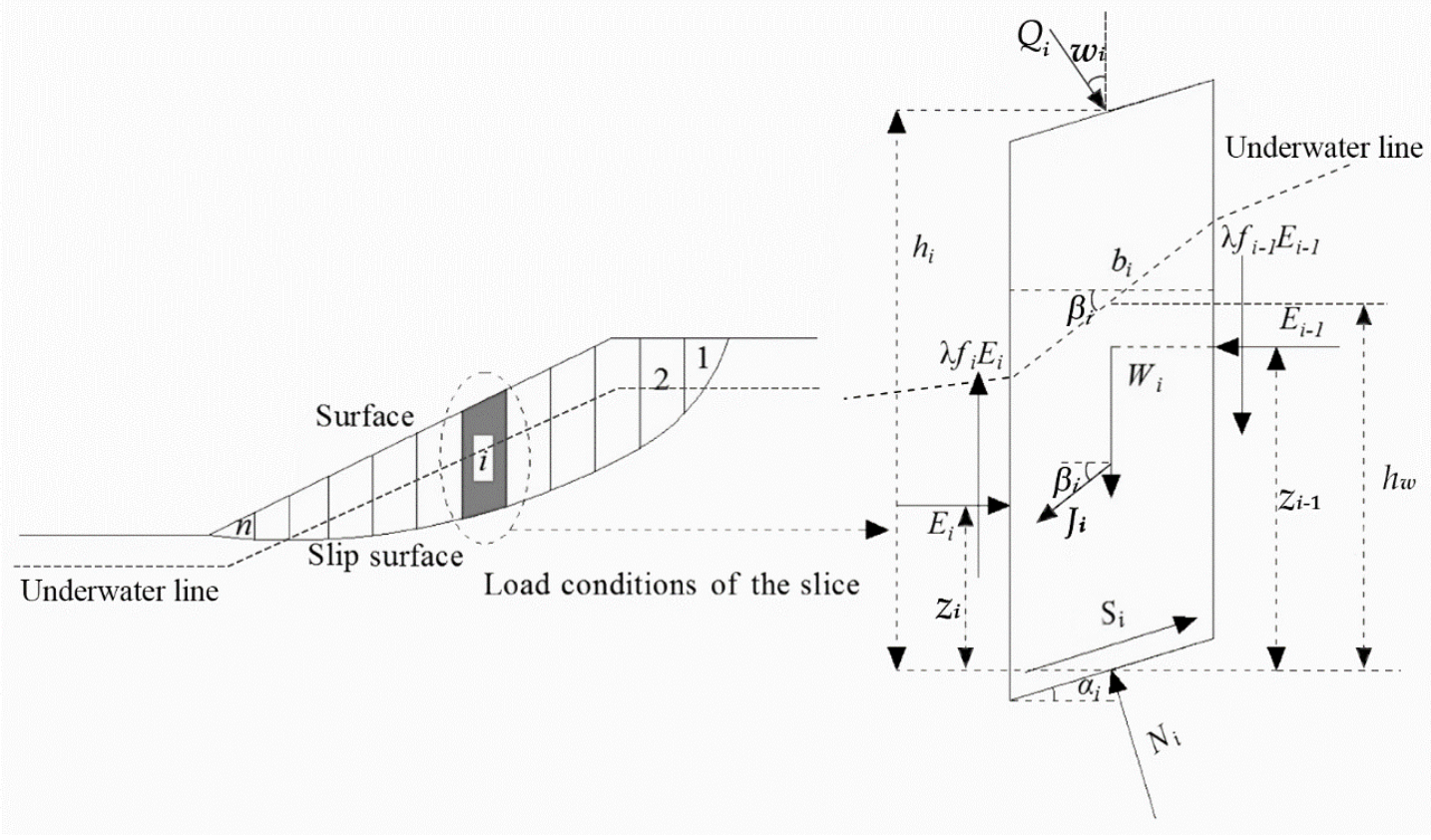

Fig. 1 Calculation principle and model of the Morgenstern-Price (M-P) Method

\section{Numerical model framework}

\subsection{Numerical model and boundary conditions}

The study are examined in this research investigation was an anti-dipping layered rock slope in the Pulang area located in Yunnan, China. In Fig. 2, I and II represent the strongly weathered carbonaceous slate and moderately weathered carbonaceous slate in the study area, which were characterized by their bedding structures. The height of the examined slope was $89 \mathrm{~m}$ and the length was $217 \mathrm{~m}$. In order to closely examine the strongly weathered carbonaceous slate, the grid size of the strongly weathered area was set to $1 \mathrm{~m}$, and the grid size of the moderately weathered area was set as $5 \mathrm{~m}$. The grid model was then divided into 7,057 nodes and 6,960 units. In order to study the characteristics of different locations, three monitoring lines and three monitoring points were set at $\mathrm{x}=25 \mathrm{~m}$ (top of the slope), $\mathrm{x}=67 \mathrm{~m}$ (middle of the slope) and $\mathrm{x}=108 \mathrm{~m}$ (bottom of the slope), respectively, with the monitoring points located on the slope surfaces below $8 \mathrm{~m}$. The boundary conditions were as follows: $\mathrm{AB}$ and $\mathrm{HF}$ were the fixed water level boundaries of $76 \mathrm{~m}$ and $19 \mathrm{~m}$, respectively; CD represented the rainfall infiltration boundary; BC and GF were the small flow boundaries; AH indicated the impermeable boundary; DE represented the water level of the tailings reservoir at $36 \mathrm{~m}$. In addition, in order to clearly reflect the real rainfall situation, the daily rainfall data from March $1^{\text {st }}$ to August $1^{\text {st }}$ of 2019 in the Pulang region were used as the rainfall conditions, as shown in Fig. 3. 


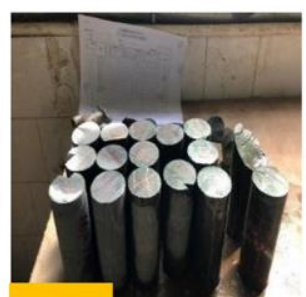

(a)
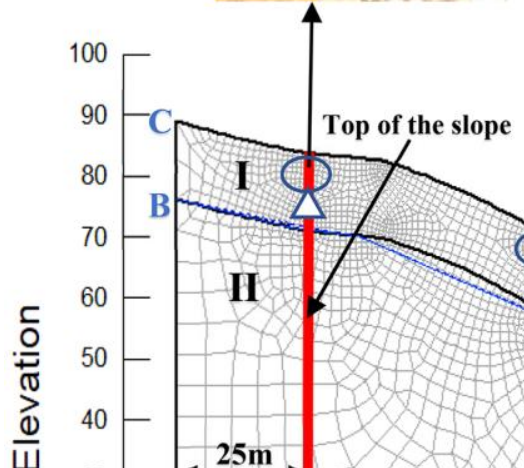

(b)

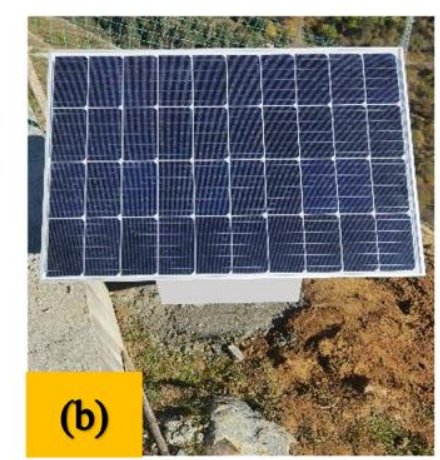

199

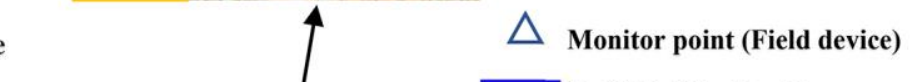

80 -

Initial infiltration line

Monitor line

Anisotropy direction

Drill hole

Water height $36 \mathrm{~m}$

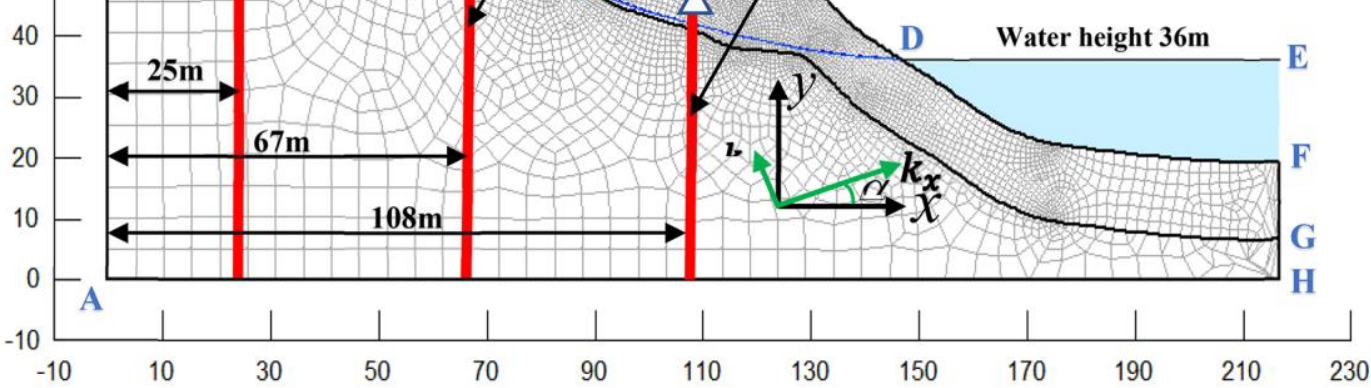

Distance

Fig. 2 Grid model

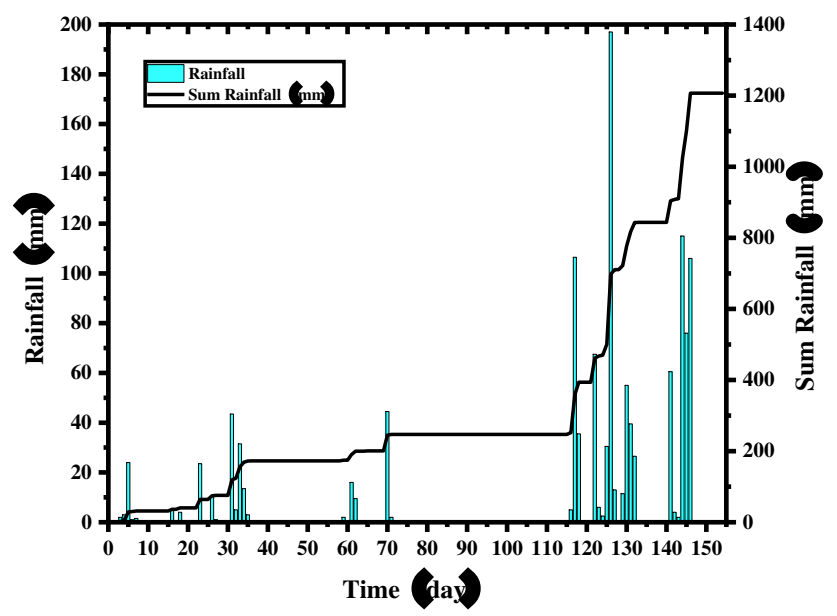

Fig. 3 Daily rainfall values from March $1^{\text {st }}$ to August $1^{\text {st }}$ of 2019

$203 \quad 3.2$ Analysis of the unsaturated layered rock mass

Previous studies have found that in practice, it is difficult to accurately measure the unsaturated characteristic curves of rock masses. Therefore, the classic water retention curve of unsaturated porous media (Brooks and Corey 1964; Fredlund and Xing 1994; V Genuchten 1980), along with relative hydraulic conductivity models (Mualem 1976) are often used to describe fractures and weakly permeable rock formations under unsaturated flow conditions. Therefore, for the soil-water characteristic curves (SWCC) of this study, the Van Genuchten model was adopted. The Van Genuchten model is as follows: 


$$
k=k_{w} \frac{\left[1-|p / a|^{n-1}\left(1+|p / a|^{n}\right)^{-m}\right]^{2}}{\left(1+|p / a|^{n}\right)^{\frac{m}{2}}}
$$

212 Where $p$ is the suction, and the unit is $\mathrm{kPa} ; \theta$ indicates the adjusted volumetric water content, and the unit is $\mathrm{m}^{-1}$; $213 \theta_{r}$ represents the residual volumetric water content, and the unit is $\mathrm{m}^{-1} ; \theta_{s}$ indicates the saturated volumetric water 214 content, and the unit is $\mathrm{m}^{-1} ; a$ denotes the fitting parameter which is closely related to the air-entry value of the unsaturated rock mass, and the unit is $\mathrm{kPa} ; n$ and $m(m=1-1 / n$ and $n>1)$ are the fitting parameters which control the slope at the inflection point in the volumetric water content function [29]; $k_{w}$ denotes the saturated hydraulic conductivity, and the unit is $\mathrm{m} / \mathrm{s}$; and $k$ indicates the adjusted hydraulic conductivity, and the unit is $\mathrm{m} / \mathrm{s}$.

Carbonaceous slate was used in this study, as shown in Fig. 4. According to the research of Chen et al. (2020), the range of the unsaturated fitting parameters of the VG model of the layered rock mass was determined, and the Geo-studio was used to numerically simulate the slope. It was concluded that the time and location of the numerical simulation are consistent with the monitoring data. The pore water pressure of the numerical simulation was compared with the monitoring data, the fitting parameters were determined, and the water retention curve was obtained (Xia et al. 2020). The water retention curve parameters are shown in Table 2 and the SWCC curves are detailed in Fig. 5.

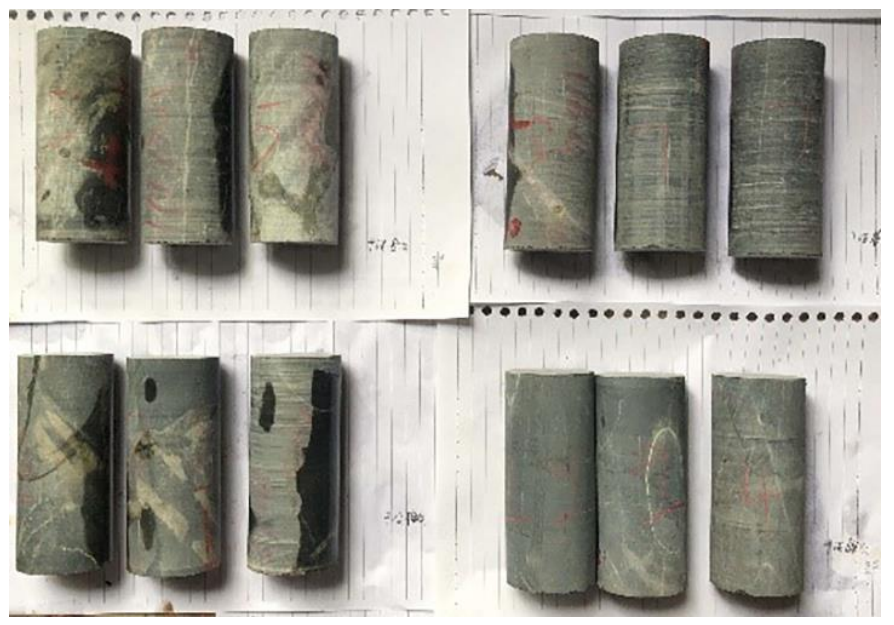

Fig. 4 Images of the carbonaceous slate samples

Table 2 Parameters of the water retention curves

\begin{tabular}{|c|c|c|c|c|c|c|c|}
\hline \multirow[t]{2}{*}{ Layer } & \multirow[t]{2}{*}{ Materials } & \multicolumn{5}{|c|}{ Fitting parameters } & \multirow{2}{*}{$\begin{array}{c}\begin{array}{c}\text { Hydraulic } \\
\text { conduction } \\
\text { coefficient }\end{array} \\
k[\mathrm{~m} / \mathrm{s}]\end{array}$} \\
\hline & & $\mathrm{A}[\mathrm{kPa}]$ & $m$ & $n$ & $\theta s$ & $\theta_{r}$ & \\
\hline I & $\begin{array}{l}\text { Strongly weathered } \\
\text { carbonaceous slate }\end{array}$ & 10 & 0.33 & 1.5 & 0.242 & 0.001 & $8.08 \times 10^{-5}$ \\
\hline II & $\begin{array}{l}\text { Moderately weathered } \\
\text { carbonaceous slate }\end{array}$ & 10 & 0.33 & 1.5 & 0.021 & 0.001 & $2.47 \times 10^{-6}$ \\
\hline
\end{tabular}




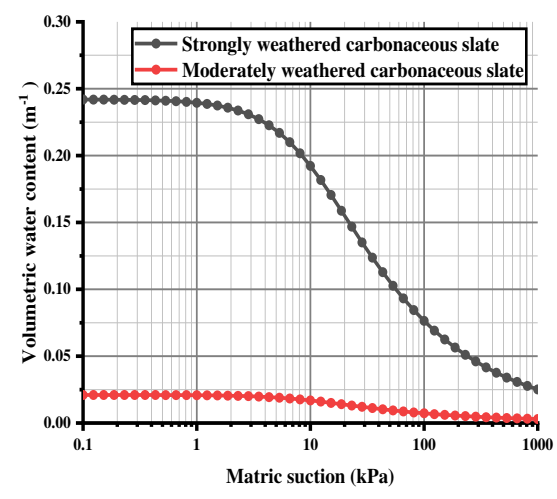

(a)

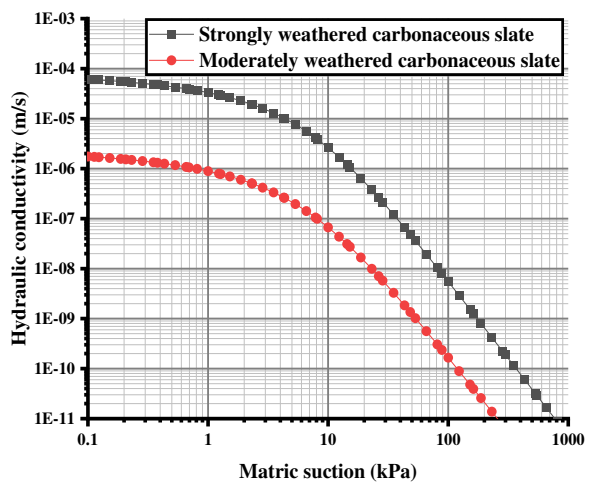

(b)

Fig. 5 SWCC curve: a Water retention curve; b Hydraulic conductivity curve.

3.3 Definition and calculation conditions of the anisotropy

The previous analysis results revealed that the previous researchs had neglected the anisotropy ratios and angles in their investigations. However, it is known that anisotropy is widespread in rock masses. In the current study, the hydraulic conductivity matrix $[C]$ was expressed as follows:

$$
[C]=\left[\begin{array}{ll}
C_{11} & C_{12} \\
C_{21} & C_{22}
\end{array}\right]
$$

In Equation (11) $, C_{11}=k_{x} \cos ^{2} a+k_{y} \sin ^{2} a, C_{22}=k_{x} \sin ^{2} a+k_{y} \cos ^{2} a$, and $C_{21}=C_{12} k_{x} \cos ^{2} a+$ $k_{y} \sin ^{2} a$. The $k_{y} / k_{x}$ and the anisotropy direction $\alpha$ were defined according to Fig. 3 , where $k_{x}$ is the horizontal hydraulic conduction coefficient; $k_{y}$ is the vertical hydraulic conduction coefficient; and $a$ indicates the direction between $k_{x}$ and the $x$ axis. Therefore, when $\alpha=0^{\circ},[C]$ is reduced to the following:

$$
[C]=\left[\begin{array}{cc}
k_{x} & 0 \\
0 & k_{y}
\end{array}\right]
$$

Equation (12) was utilized in the present study, and only the anisotropy ratio $k_{r}=k_{y} / k_{x}$ was considered. However, the definition of rock mass anisotropy is not only the anisotropy ratio, but also the anisotropy angle. Therefore, in order to better study the anisotropy of the layered rock masses, including the anisotropy ratio $k_{r}$ and the anisotropy direction $\alpha$, the calculation conditions shown in Table 3 were implemented. Then, by combining the findings of previous studies (Yao et al. 2020; Cheng et al. 2020; Yu et al. 2020), the anisotropy ratio $k_{r}=0.01$, $0.02,0.1$, and 1 and the anisotropy direction $\alpha=0^{\circ},-15^{\circ},-30^{\circ},-45^{\circ},-60^{\circ},-75^{\circ}$, and $-90^{\circ}$ were successfully determined. The failure criterion of the rock mass layered slope simulations adopted the Mohr-Coulomb Criterion, and the rock mass strength parameters were determined from the geotechnical test results, as detailed in Table 4 .

\begin{tabular}{|c|c|c|}
\hline Rock types & Anisotropy ratio $k_{r}=k_{y} / k_{x}$ & Anisotropy angle $\alpha\left[^{\circ}\right]$ \\
\hline $\begin{array}{c}\text { Strongly weathered carbonaceous } \\
\text { slate }\end{array}$ & {$\left[\begin{array}{lllll}0.01 & 0.02 & 0.1 & 1\end{array}\right]$} & {$\left[\begin{array}{lllllllll}0 & -15 & -30 & -45 & -60 & -75 & -90\end{array}\right]$} \\
\hline
\end{tabular}

Table 3 Calculation conditions

Table 4 Rock mass strength parameters

\begin{tabular}{cccccc}
\hline Rock types & $\begin{array}{c}\text { Elastic } \\
\text { modulus } \\
{[\mathrm{Mpa}]}\end{array}$ & $\begin{array}{c}\text { Poisson } \\
\text { ratio }\end{array}$ & $\begin{array}{c}\text { Unit } \\
\text { weight }\left[\mathrm{kN} / \mathrm{m}^{3}\right]\end{array}$ & Cohesion[kPa] & $\begin{array}{c}\text { Friction } \\
\text { angle }\left[{ }^{\circ}\right]\end{array}$ \\
\hline $\begin{array}{c}\text { Strongly weathered } \\
\text { carbonaceous slate }\end{array}$ & 2644.9 & 0.38 & 22.4 & 93.6 & 33.3 \\
\hline $\begin{array}{c}\text { Moderately weathered } \\
\text { carbonaceous slate }\end{array}$ & 5561 & 0.35 & 26.5 & 120 & 35 \\
\hline
\end{tabular}




\subsection{Initial conditions}

The determination of the initial conditions was very important for the next step of the numerical simulation. In order to make the initial matrix suction more in line with the actual situation, this study calculated the maximum pore water pressure of $-25 \mathrm{kpa},-50 \mathrm{kpa},-75 \mathrm{kpa}$ and the annual average rainfall of $0.6 \mathrm{~mm} / \mathrm{h}$ in the Pulang area. The infiltration volume was numerically simulated and the pore pressure changes in the slate are shown in Fig. 6. It can be seen from the figure that the pore water pressure changes of the average annual rainfall were the closest to a maximum pore water pressure of $-75 \mathrm{kpa}$. Therefore, the initial pore water pressure levels of all this study's simulation experiments were set as $-75 \mathrm{kpa}$, which was to be consistent with the actual situation in the Pulang area.

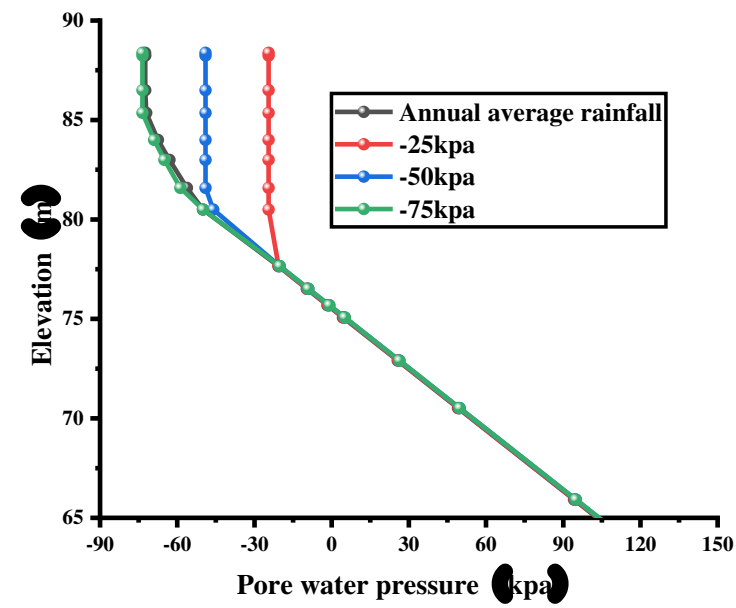

Fig. 6 Initial pore pressure distribution

4.2 Effects of the hydraulic conductivity anisotropy on the seepage characteristics

In accordance with the calculation conditions detailed in Table 3, a total of 28 numerical simulations were carried out, and 84 sections of volumetric water content variations were obtained. Figure 8 shows the changes in the volumetric water content with different values of $\alpha$ when $k_{r}=0.01$ and $k_{r}=0.1$, respectively. The goal was to illustrate the effects of the anisotropy direction $\alpha$ on the seepage characteristics. In Figure 9 , the volumetric water content changes with different values of $k_{r}$ when $\alpha=-15^{\circ}, \alpha=-45^{\circ}$ and $\alpha=-90^{\circ}$ are shown in order to illustrate the effects of the anisotropy ratio $k_{r}$ on the seepage characteristics. The rainfall infiltration depth (RID) and the maximum surface water content (MWCS) are defined. Figure 11 shows the changes of MWCS and RID of rock slopes with different $k r$ and $\alpha$.

\subsubsection{Analysis of the volumetric water content}

Fig. 7 shows the changes in the volumetric water content of the carbonaceous slate in different regions under the conditions of different anisotropy angle $\alpha$ values. The initial state consisted of the distribution of water content of the slope before the rain, and the remainder was the state of the distribution of water content after the rain had stops.

From the aspect of the top of the slope, the volumetric water content of the slope surfaces was observed to decrease as the angle $\alpha$ decreased. This was due to the fact that the hydraulic conductivity in the horizontal direction was greater than that in the vertical direction. It was found that when the angle $\alpha$ was equal to $0^{\circ}$, the vertical penetration was the smallest. Subsequently, following rainfall events, rainwater tended to accumulate on the surfaces of the slope. However, with decreases in the angle $\alpha$, the vertical permeability continuously increased, and the rainwater was more likely to seep into the deeper parts of the slope. It was determined from the comparison results of the different anisotropy ratios that when the anisotropy ratio was larger (for example, $k_{r}=0.1$ ), the 
influencing effects of the rainfall on the volumetric water content were mainly concentrated on the surfaces of the slope. In addition, when the anisotropy was relatively small (for example, $k_{r}=0.01$ ), the rainfall not only affected the volumetric water content of the surfaces, but also strongly affected the volumetric water content of the deeper parts of the slope, particularly at $-15^{\circ}$ and $-30^{\circ}$.

When examining the middle sections of the slope, it was found that the volumetric water content was affected by both rainfall infiltration and rainfall discharge at the top of the slope. Furthermore, as previously described, as the angle $\alpha$ decreased, the volumetric water content of the middle sections of the slope gradually decreased. However, when $\alpha=-15^{\circ}$, the volumetric water content of the surface area reached the maximum. In addition, when the anisotropy was relatively small (for example, $k_{r}=0.01$ ), the impacts of the rainfall events on the deeper parts of the slope were found to be more severe.

For the bottom of the slope, when the anisotropy was relatively small (for example, $k_{r}=0.01$ ), the rainfall was found to have a severe effects on the volumetric water content of the deeper parts of the slope. When the plane was inclined at $-15^{\circ}$ or $-30^{\circ}$, the volumetric water content levels of the deeper parts of the slope body were low, which resulted in decreased excretion. As a result, this had led to large changes in the volumetric water content levels of the surfaces in the bottom of the slope.

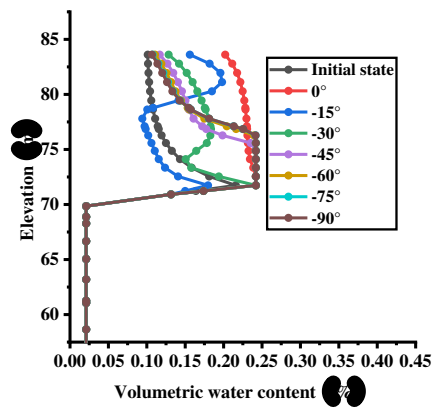

(a)

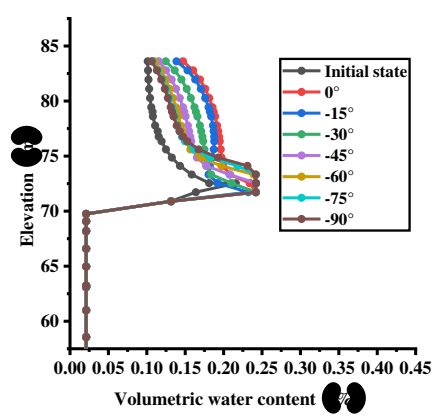

(d)

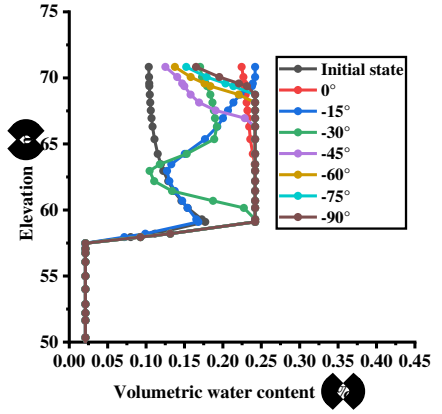

(b)

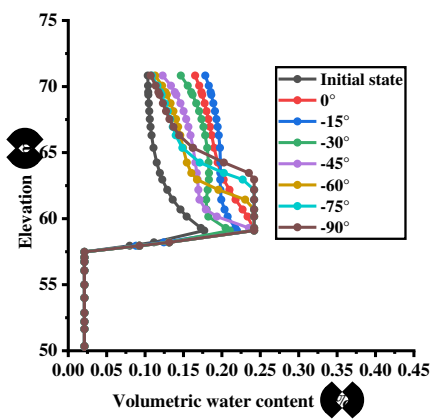

(e)

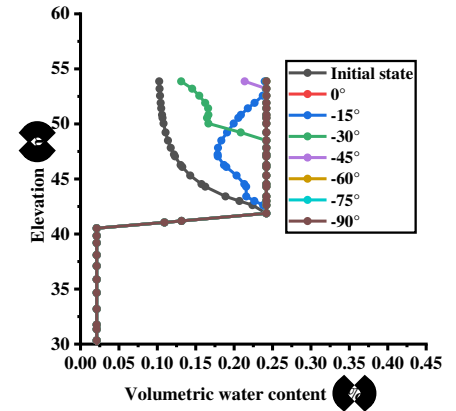

(c)

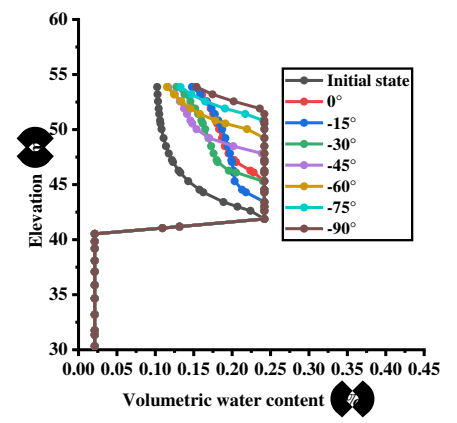

(f)

Fig. 7 Variations in the volumetric water content levels under different $\alpha$ values for the anti-dipping carbonaceous slate slopes: a Top of the slope with $k_{r}=0.01$, b Middle of the slope with $k_{r}=0.01$, $\mathbf{c}$ Bottom of the slope with $k_{r}$ $=0.01, \mathbf{d}$ Top of the slope with $k_{r}=0.1$, $\mathbf{e}$ Middle of the slope with $k_{r}=0.1, \mathbf{f}$ Bottom of the slope with $k_{r}=0.1$

Fig. 8 shows that the volumetric water content of the slope was affected by the anisotropy ratio $k_{r}$. At the top of the slope, the volumetric water content of the slope surfaces decreased with the increases in the anisotropy ratio $k_{r}$, due to fact that the $k_{r}$ increases had led to weakening of the horizontal penetration. Consequently, an accumulation of rainwater on the surfaces of the slope. This study determined from the comparison results of the different $\alpha$ angles, that when the value of $\alpha$ is small (for example, $\alpha=-15^{\circ}$ ), the rainfall had strong influencing effects on the deeper parts of the slope, particularly at $k_{r}=0.01$ and $k_{r}=0.02$. The reason for these effects were related to the fact that when $k_{r}$ was small, the vertical permeability was reduced, and the rainwater had slowly seeped into the deeper parts of the slope. This had caused the groundwater levels to rise slowly, forming a negative pressure zone in the deeper parts of the slope.

It was observed that for the middle sections of the slope, the variation range of the volumetric water content was larger than that of the top sections of the slope. The turning point of the volumetric water content curve appeared in the deeper parts of the slope. The humidity conditions in the area above those points began to change 

rainfall had ceased.

In addition, due to terrain problems in the bottom region of the slope, the initial water level was relatively small. The bottom area of the slope was not only be affected by rainfall, but also by the drainage of rainwater from the middle section of the slope. Therefore, the speed at which the foot of the slope reached its saturation point, along with the rising of the groundwater, were faster than in the other sections.

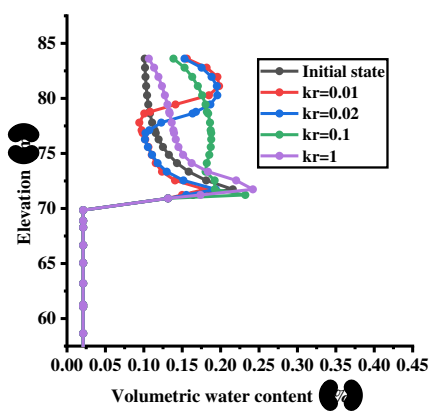

(a)

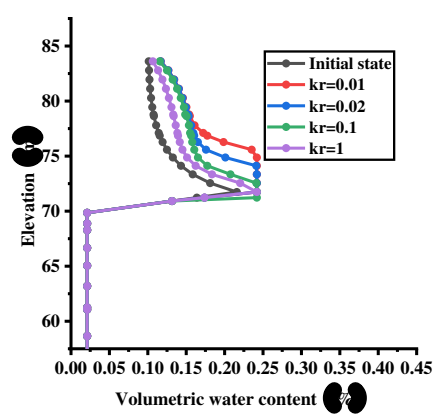

(d)

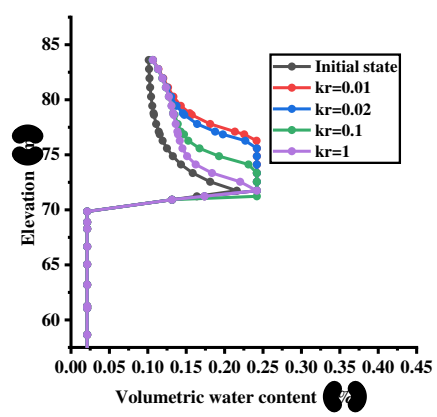

(g)

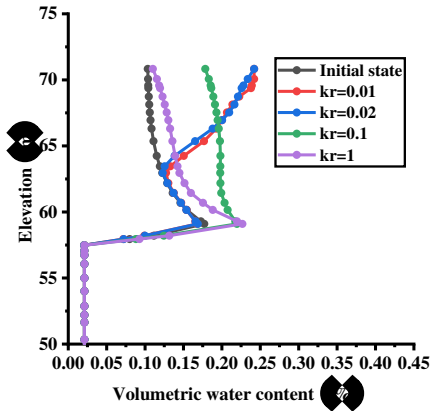

(b)

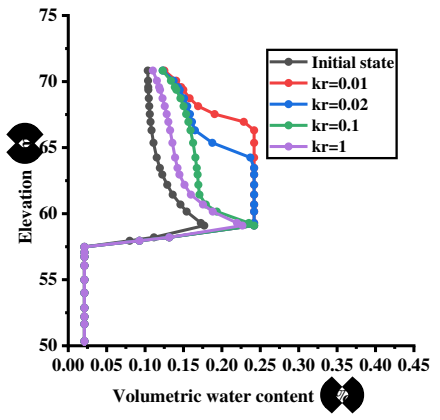

(e)

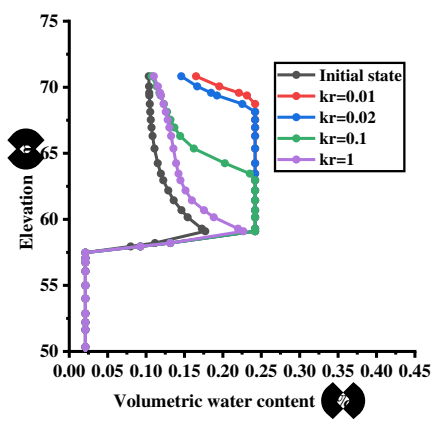

(h)

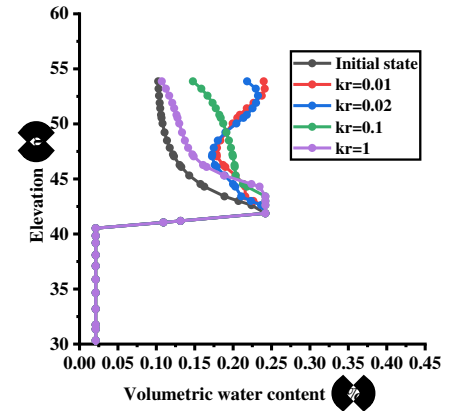

(c)

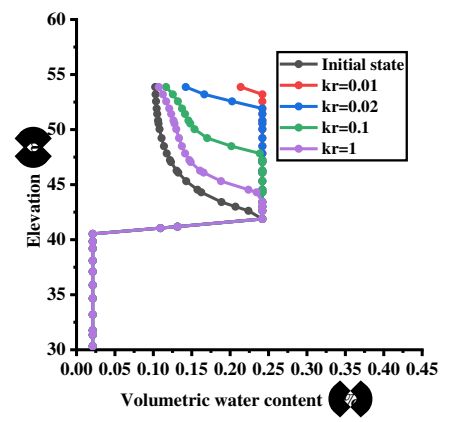

(f)

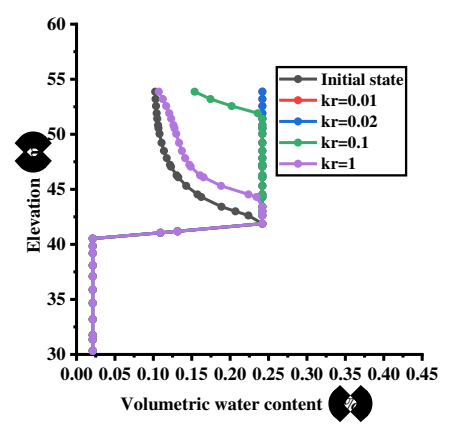

(i)

Fig. 8 Volumetric water content levels at different positions on the anti-dipping carbonaceous slate slope under different $\mathrm{kr}$ values with $\alpha=-15^{\circ} 、 \alpha=-30^{\circ}$ and $\alpha=-45^{\circ}$ : a Top of the slope with $\alpha=-15^{\circ}$, b Middle of the slope with $\alpha=-15^{\circ}$, c Bottom of the slope with $\alpha=-15^{\circ}, \mathbf{d}$ Top of the slope with $\alpha=-45^{\circ}$, e Middle of the slope with $\alpha=-45^{\circ}, \mathbf{f}$ Bottom of the slope with $\alpha=-45^{\circ}, \mathbf{g}$ Top of the slope with $\alpha=-90^{\circ}, \mathbf{h}$ Middle of the slope with $\alpha=-$ $90^{\circ}, \mathbf{i}$ Bottom of the slope with $\alpha=-90^{\circ}$.

\subsubsection{Analysis of the rainfall infiltration depth and maximum surface water content levels}

It was concluded from the aforementioned results that the hydraulic conductivity anisotropy ratios $k_{r}$ and the anisotropy directions $\alpha$ had major influences on the permeability of the anti-dipping slope. In order to further study the influencing effects of different $k_{r}$ and $\alpha$ on the infiltration of rock slopes, the rainfall infiltration depths (RID) and maximum surface water content (MWCS) levels were defined. As shown in Fig. 9, the volumetric water content levels on the slope had changed with time. As the rainfall continued, the volumetric water content levels of the slope gradually increased until the rainfall ended. Therefore, the MWCS was defined in order to represent the saturation of the slope surfaces, which was the maximum water content of the surfaces after the 
rainfall had ceased. During the rainfall process, the rainwater had infiltrated into deeper areas of the slope. The RID was used to express the impacts of the rainfall at a specific depth in the slope. This depth was the height from the turning point to the slope surfaces. The data detailed in Fig. 9 were taken at the water conductivity anisotropy $k_{r}=0.1$ and $\alpha=-60^{\circ}$. It can be seen in the figure that for the strongly weathered carbonaceous slate, the rainwater had easily penetrated the layers, and the differences were large. It should be noted that the volumetric water content of the deeper slope areas was observed to change drastically at the 100-days and 150-days points. This was determined to be due to no rainfall occurring for a period of time prior to those timeframes.

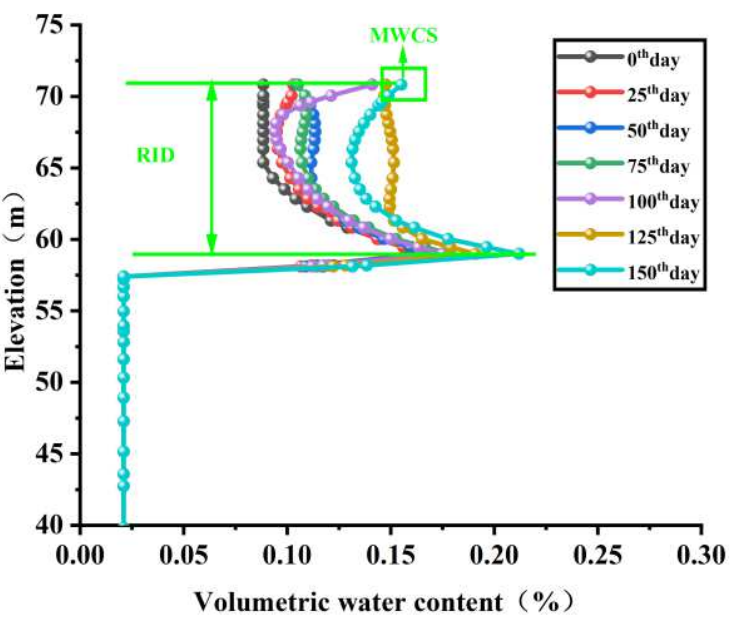

Fig. 9 Variations in the volumetric water content levels 


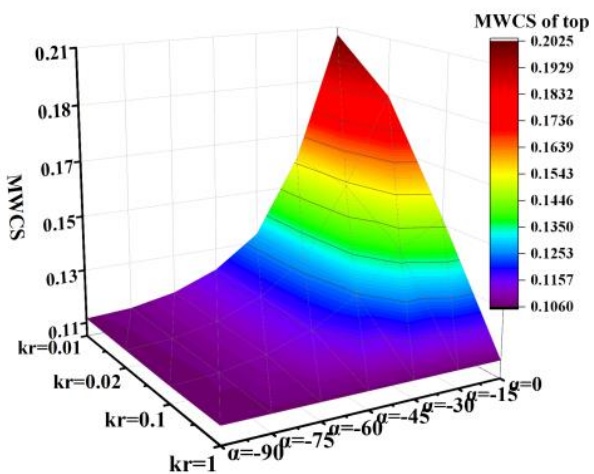

(a)

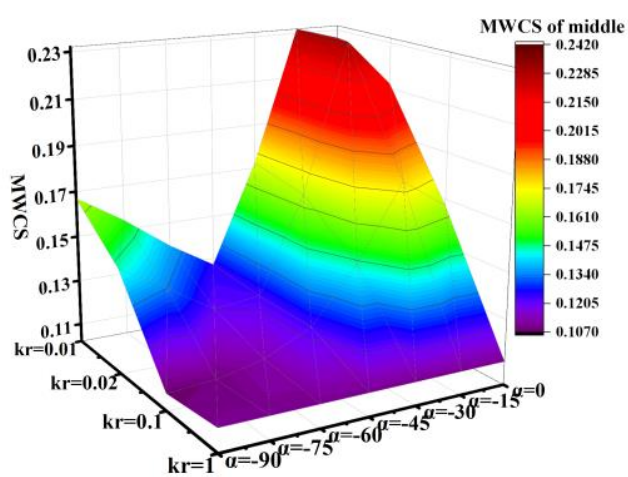

(b)

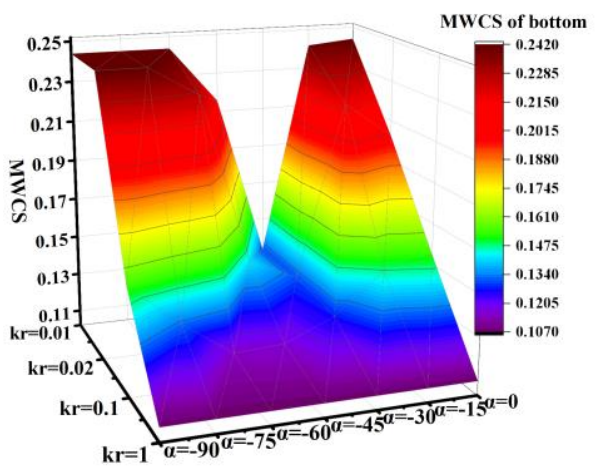

(c)

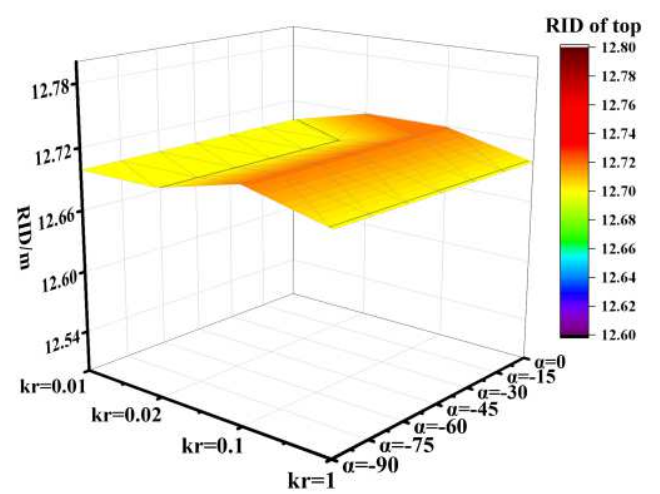

(d)

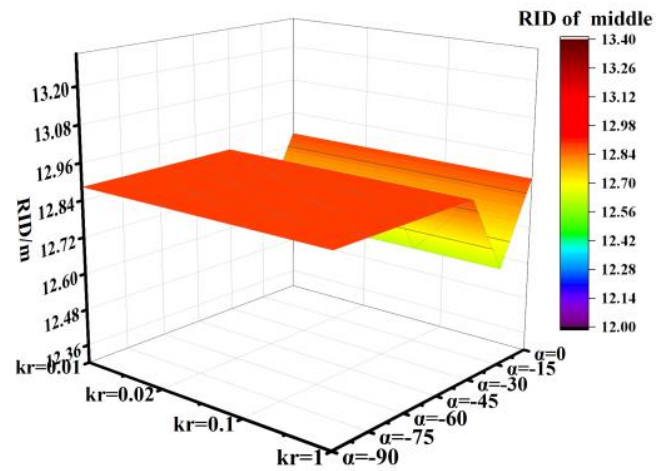

(e)

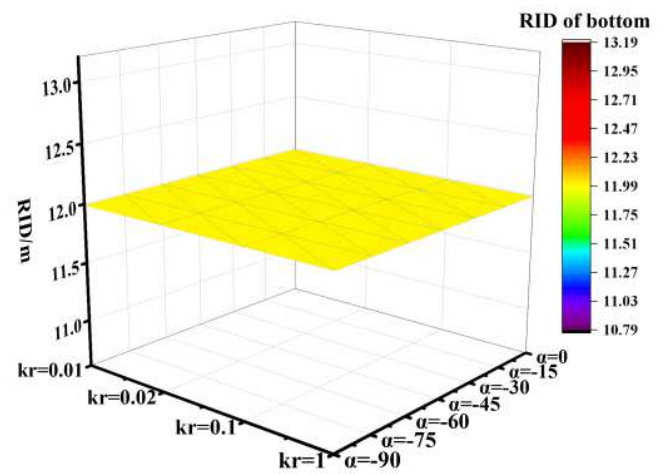

(f)

Fig. 10 Variations in the MWCS and RID with different $\mathrm{kr}$ and $\alpha$ : a MWCS of top of the slope, $\mathbf{b}$ MWCS of the middle of the slope, $\mathbf{c}$ MWCS of the bottom of the slope, $\mathbf{d}$ RID of top of the slope, $\mathbf{e}$ RID of middle of the slope, f RID of the bottom of the slope.

Fig. 10 details the changes in the MWCS and RID values of the rock slope with different $k_{r}$ and $\alpha$. For the examined anti-dipping carbonaceous slate slope, the MWCS gradually decreased as the $k_{r}$ increased and the $\alpha$ decreased. However, when reaching the bottom of the slope, the value of the MWCS was observed to become larger than those the top and the middle sections of the slope, which indicated that the bottom of the slope was more likely to reach its saturation point more quickly due to its height during the rainfall. It was also observed that for the broken center and the bottom of the carbonaceous slate inverted layer, when $\alpha=-45^{\circ}$ and the $k_{r}$ was small, the MWCS tended to have a smaller value. This was attributed to the fact that when $\alpha=-45^{\circ}$, the slope was perpendicular, and the infiltration of the slope was consistent with the infiltration in the horizontal direction. In other words, the surface areas of the slope experienced rainfall in two directions. However, when the anisotropy angle was greater than $-45^{\circ}$, the horizontal infiltration was much larger than the vertical infiltration. In contrast, when the anisotropy angle was less than $-45^{\circ}$, the vertical penetration was much greater than the horizontal penetration. The maximum values and change rates of the MWCS are shown in Table 5. The change range of the MWCS at the top of the slope was between 0.1064 and 0.202 , and the change rate was $23 \%$. The range of the MWCS in the middle of the slope was between 0.10733 and 0.23 , and the rate of change was $114 \%$. The range of the MWCS at the bottom of the slope was determined to be between 0.10704 and 0.242 , and the rate of change 
was $126 \%$. Therefore, it was found that the change rates of the MWCS were larger in the middle and bottom sections of the slope, which indicated that the MWCS in the middle and bottom sections of the slope were more

373 affected by the $k_{r}$ and $\alpha$.

Table 5 MWCS maximum and minimum values and rates of change

\begin{tabular}{cccc}
\hline Slope position & \multicolumn{1}{c}{ Minimum value of MWCS } & Maximum value of MWCS & Rate of change \\
\hline Top of the slope & 0.1064 & 0.202 & $23 \%$ \\
Middle of the slope & 0.10733 & 0.230 & $114 \%$ \\
Bottom of the slope & 0.10704 & 0.242 & $126 \%$ \\
\hline
\end{tabular}

The RID changes of the anti-dipping carbonaceous slate slope are detailed in Fig. 10d, Fig. 10e, and Fig. 10f. Table 6 shows the maximum values and change rates of the RID. It was found that under different conditions of $k_{r}$ and $\alpha$, the variation range of the slope top RID was between 12.69907 and $12.71925 \mathrm{~m}$, and the variation rate was $0.16 \%$. The range of the RID in the middle section of the slope was between 12.62164 and $12.88343 \mathrm{~m}$, and the rate of change was determined to be $2.07 \%$. In addition, the RID at the bottom of the slope was not observed to change. The RID was $11.99025 \mathrm{~m}$, and the rate of change was $0 \%$. Therefore, this study determined that the maximum value of the RID appeared in the middle section of the slope, and the minimum value appeared at the bottom of the slope. The RID in the middle section of the slope had the largest rate of change, which indicated that the RID in the middle area of the slope was most affected by the $k_{r}$ and $\alpha$. Furthermore, it was observed that the RID change rate at the bottom of the slope was the smallest, which indicated that the RID at the bottom was the least affected by the $k_{r}$ and $\alpha$.

Table 6 RID maximum and minimum values and rates of change

\begin{tabular}{|c|c|c|c|}
\hline Slope position & Minimum value of RID & Maximum value of RID & Rate of change \\
\hline Top of the slope & $12.69907 \mathrm{~m}$ & $12.71925 \mathrm{~m}$ & $0.16 \%$ \\
\hline Middle of the slope & $12.62164 \mathrm{~m}$ & $12.88343 \mathrm{~m}$ & $2.07 \%$ \\
\hline Bottom of the slope & $11.99025 \mathrm{~m}$ & $11.99025 \mathrm{~m}$ & $0 \%$ \\
\hline
\end{tabular}

4.3 Influencing effects of the hydraulic conductivity anisotropy on the displacements of the anti-dipping slopes

In the present study, based on the fluid-solid coupling theory, it was considered that the anti-dipping layered rock mass would produce corresponding displacements under the action of fluid. In order to highlight the influencing effects of the anisotropy angles and anisotropy ratios on the horizontal displacements, anisotropy ratio $k_{r}=0.1$ was selected, along with anisotropy angle $\alpha=-45^{\circ}$. The changes are shown in Fig. 11 . The initial state was the horizontal displacements of the slope when there was no rainfall, and the remainder was the horizontal displacements when the rainfall stopped. It can be seen in the Fig. 11 that the displacements in the slope and the slope bottom were relatively large, while the displacements of the slope top were relatively small. Therefore, if any landslides were to occur in the slope due to rainfall, they would tend to be traction landslides. When $\alpha$ does not change, then as $k_{r}$ decreases, there will be differences in the horizontal displacements of the slope. In the top area of the slope, the horizontal displacements would increase with the increases in elevation, and the horizontal displacements of the slope could be underestimated in the isotropic state. It was observed in this study that for the middle and bottom areas of the slope, when $k_{r}=0.01$ and $k_{r}=0.02$, the horizontal displacements first increased, and then decreased with the elevation. The maximum displacement was approximately $17 \mathrm{~m}$ from the surface. However, when $k_{r}=0.1$ and $k_{r}=1$, the horizontal displacements increased with the increase in elevation, and the maximum displacement was on the slope surface. At that time, the horizontal displacements of the slope could be overestimated in the isotropic state.

It was found in this study that when $k_{r}$ was constant and the anisotropy angle was less than $-45^{\circ}$, the horizontal displacement produced by the slope were smaller. In addition, when the anisotropy angle was greater than $-45^{\circ}$, the slope produced larger horizontal displacements, particularly at $-15^{\circ}$ and $-30^{\circ}$. This was due to the fact that the horizontal permeability in that state was much greater than the permeability in the vertical direction. Also, due to the existence of elevation difference, the rainwater flowed all the way to the foot of the slope. Therefore, the horizontal displacements at the bottom of the slope were larger than those at the top and middle sections of the slope. 


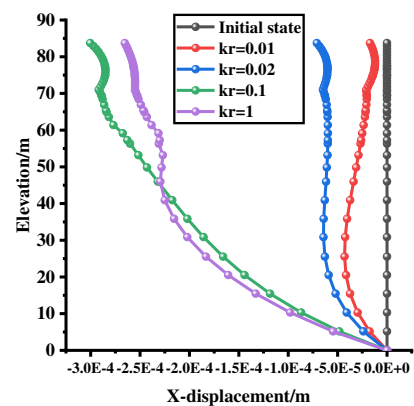

(a)

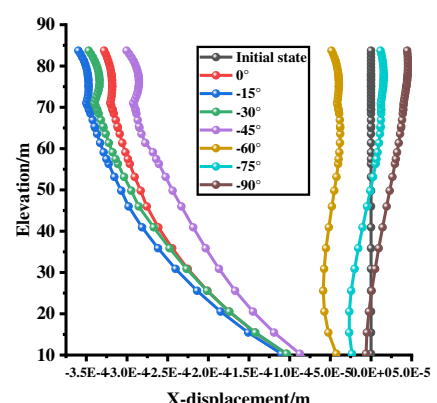

(d)

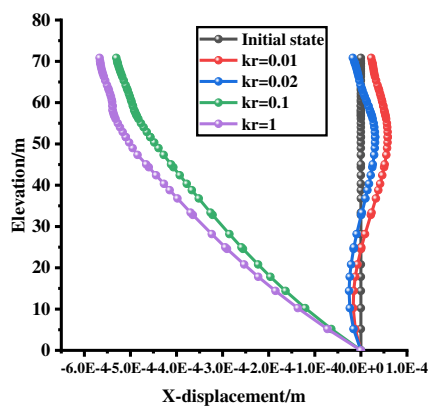

(b)

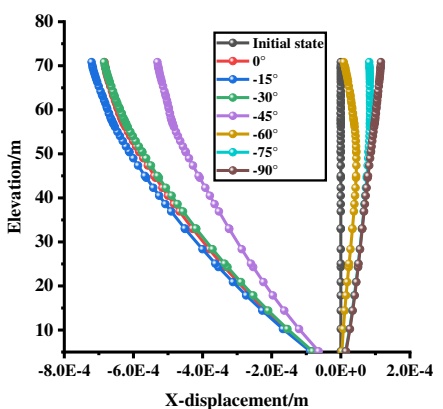

(e)

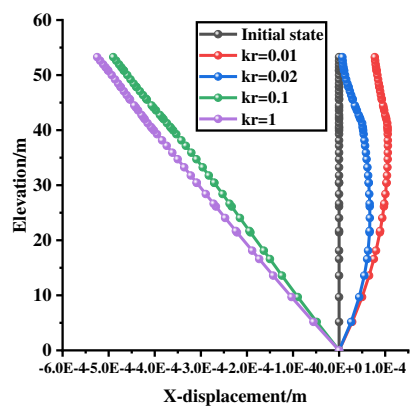

(c)

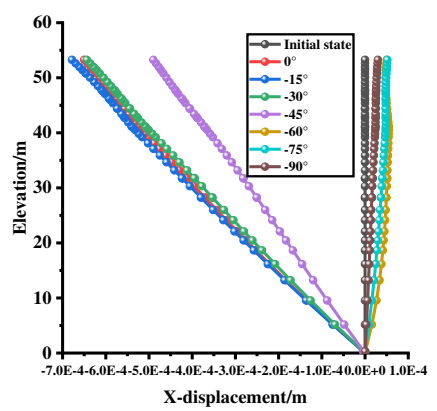

(f)

Fig. 11 Variations in the $\mathrm{x}$-displacement under different $\mathrm{kr}$ and $\alpha$ values for anti-dipping carbonaceous slate slopes: a Top of the slope with $\alpha=-45^{\circ}$, b Middle of the slope with $\alpha=-45^{\circ}$, c Bottom of the slope with $\alpha=-45^{\circ}, \mathrm{d}$ Top of the slope with $k_{r}=0.1$, e Middle of the slope with $k_{r}=0.1$, $\mathrm{f}$ Bottom of the slope with $k_{r}=0.1$

In the current investigation, for the purpose of quantitative research, the maximum horizontal displacement (MHD) of an anti-dipping carbonaceous slate slope under different anisotropic permeability characteristics, along with the changes in the MHD under different conditions, are detailed in Fig. 12. The influencing effects of the permeability anisotropy on the MHD were found to vary with the slope position (for example, the top, middle, and bottom sections of the slope). The MHD was largest at the foot of the slope, smaller at the middle of the slope, and the smallest at the top of the slope. As shown in Table 7, for the examined anti-dipping carbonaceous slate slope, considering only the top, middle, and bottom of the slope, the differences between the maximum and minimum MHD were $60.9 \%, 37.8 \%$ and $29.8 \%$, respectively. Also, considering the two factors of the $k_{r}$ and $\alpha$, the differences of the anti-dipping carbonaceous slate slope were $71.4 \%, 46.3 \%$ and $39.7 \%$, respectively. It was found that under the conditions that only the anisotropy ratio $k_{r}$ and the anisotropy ratio $k_{r}$ and the rock formation dip $\alpha$ were considered, the MHD values differed greatly. Therefore, this study determined that in cases of antidipping layered rock slopes, both the anisotropy ratios and rock layer dip angles should be considered in deformation analysis.

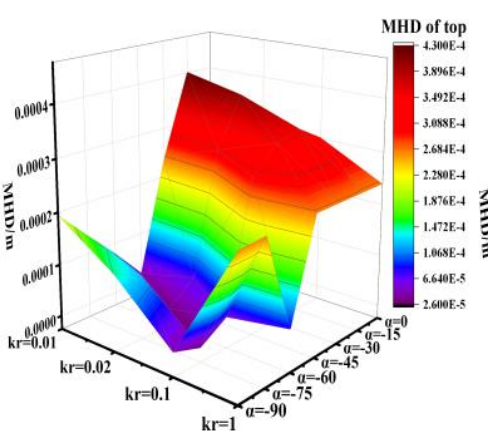

(a)

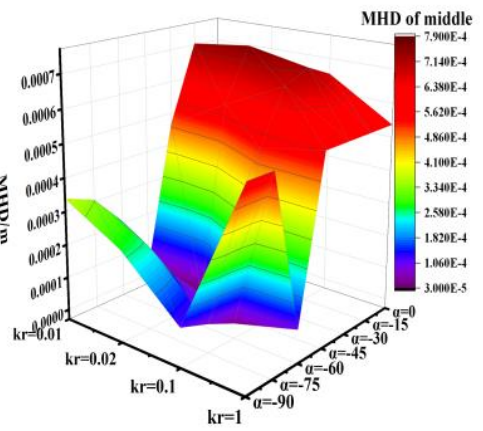

(b)

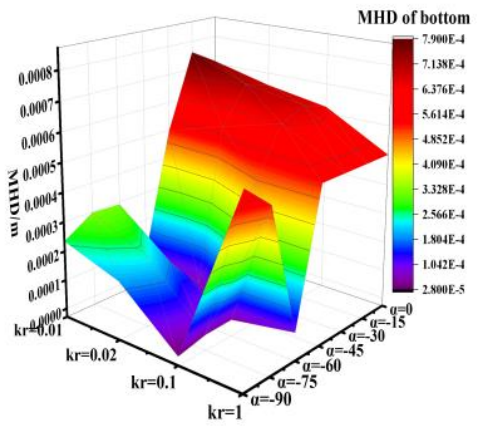

(c)

Fig. 12 Variations in the maximum horizontal displacement (MHD) under different $\mathrm{kr}$ and $\alpha$ values: a Top of the 
Table 7 MHD considering $k_{r}$ only and considering the differences between the $k_{r}$ and $\alpha$

\begin{tabular}{cccc}
\hline & Analysis content & Only Consider $k_{r}$ & Consider $k_{r}$ and $\alpha$ \\
\hline MHD (Top) & Carbonaceous slat slope & $60.9 \%$ & $71.4 \%$ \\
MHD (Middle) & Carbonaceous slat slope & $37.8 \%$ & $46.3 \%$ \\
MHD (Bottom) & Carbonaceous slat slope & $29.8 \%$ & $39.7 \%$ \\
\hline
\end{tabular}

4374.4 Influencing effects of the anisotropy of hydraulic conductivity on the stability of anti-dipping rock slopes

Fig. 13 shows the changes in the safety factors (SF) of a carbonaceous slate slope under different permeability anisotropy ratios $k_{r}$ and direction angles $\alpha$. In order to highlight the influencing effects of the anisotropy angles and the anisotropy ratios on the safety factors, $\alpha=-45^{\circ}$ was selected to change the anisotropy ratio $k_{r}$, and $k_{r}=0.1$ was selected to change the anisotropy angle $\alpha$. It was found that when $\alpha$ was constant, as $k_{r}$ decreased, and the safety factors also gradually decreased. It was also noted that when $k_{r}=1$, the safety factor of the slope tended to be overestimated in the isotropic state. Furthermore, when $k_{r}$ did not change, as $\alpha$ decreased, the safety factors also gradually decreased. This was due to the fact that the negative dip angle of the rock formation had increased, and the permeability of the rock mass increased, as well as the groundwater level, which led to the $\alpha$ decreasing in soil strength and SF. It was also found that the safety factor curves had fluctuated, as illsetrated in Fig. 13. This was attributed to the fluctuation intervals during the heavy rain events in the area. Following the heavy rain, the rainwater infiltrated and accumulated on the surfaces of the slope, forming a very large unsaturated zone. The back pressure impacted the soil body reinforcement. However, after a period of rain, the safety factors of the slope returned to a stabilized state.

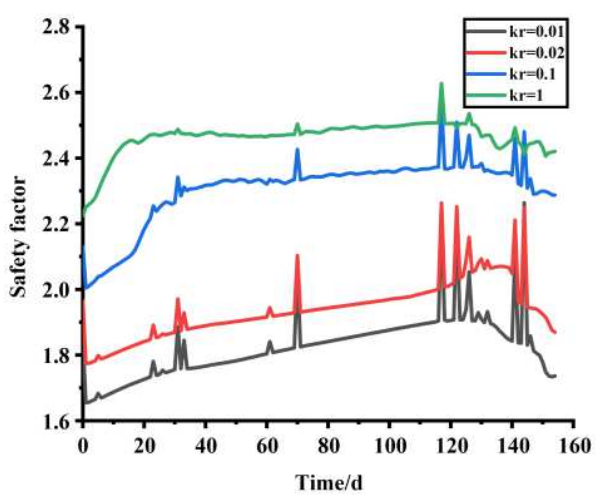

(a)

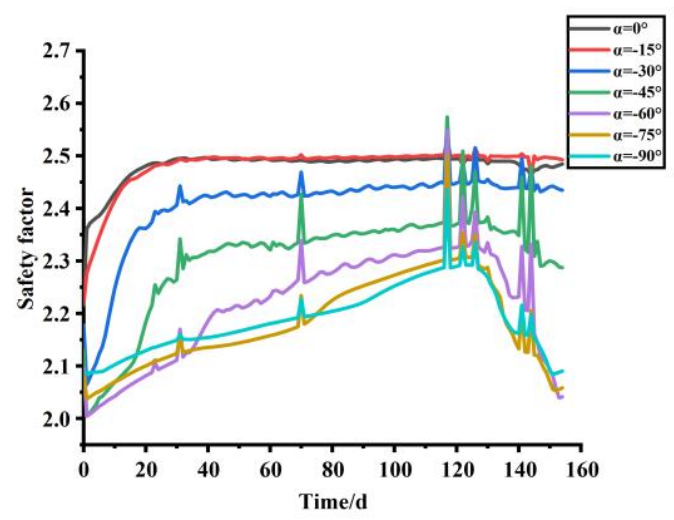

(b)

Fig. 13 Variations in the safety factors under different $k_{r}$ and $\alpha$ values for anti-dipping carbonaceous slate slope: a Slope with $\alpha=-45^{\circ}$, b Slope with $k_{r}=0.1$

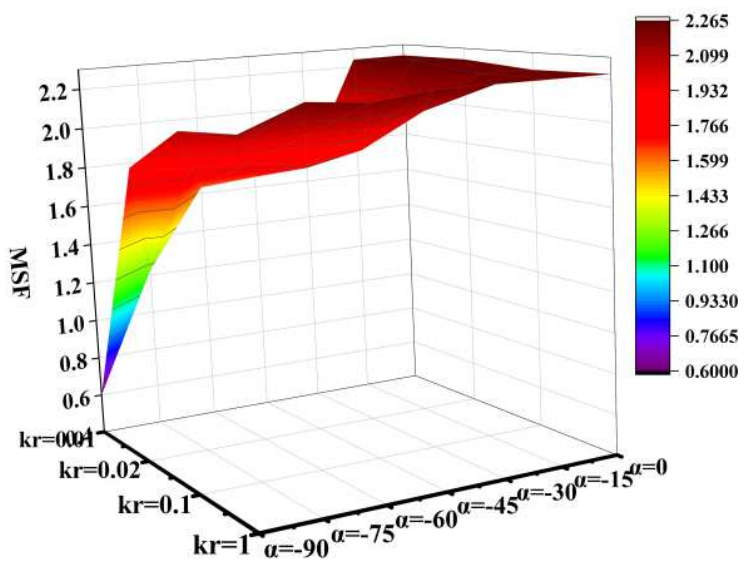

Fig. 14 Variations in the SF for anti-dipping carbonaceous slate slopes 
The changes of MSF under different conditions are shown in Fig. 14. It can be seen in the figure that as the $k_{r}$ and $\alpha$ decreased, the MSF dropped to a minimum. As detailed in Table 8, when considering only the $k_{r}$, the differences between the maximum and minimum MSF was $70.4 \%$ for the carbonaceous slate slope. However, considering the two conditions of $k_{r}$ and $\alpha$, the difference of the carbonaceous slate slope was $77.2 \%$. It can be found that under the conditions in which only the anisotropy ratios $k_{r}$ were considered, and under the conditions in which the anisotropy ratios $k_{r}$ and the rock inclination anglse $\alpha$ were both considered, the MSF values differed greatly. Therefore, for anti-dipping layered rock slopes, it is recommended that both the anisotropy ratios and rock layer dip angles are considered in stability analysis processes.

Table 8 MSF only considers the $k_{r}$ and considers the differences between the $k_{r}$ and $\alpha$

\begin{tabular}{cccc}
\hline & Analysis content & Only Consider $k_{r}$ & Consider $k_{r}$ and $\alpha$ \\
\hline MSF & Carbonaceous slate slope & $70.4 \%$ & $77.2 \%$ \\
\hline
\end{tabular}

\section{Conclusions}

This research investigation considered the influencing effects of different anisotropy ratios and the hydraulic conductivity of the anisotropy angles, and numerically simulated the seepage characteristics, deformations and stability levels of the an anti-dipping layered carbonaceous slate slope in the Pulang area, of southwestern China. The research results were as follows:

(1) The initial conditions was very important for the subsequent calculations of the unsaturated seepage of the anti-dipping layered rock slope. This study verified that the maximum initial matrix suction of $-75 \mathrm{kPa}$ carbonaceous slate could be selected for the numerical simulations, which was consistent with the actual situation.

(2) The anisotropy ratios of the bedding plane and the inclination angles of the strata had major influences on the seepage of the anti-dipping layered rock slope.

(3) The maximum surface water content (MWCS) levels and the rainfall infiltration depths (RID) were defined in order to characterize the seepage characteristics of anti-dipping layered rock slopes. The MWCS gradually decreased with the increases in the bedding plane anisotropy ratios and the decreases of the anisotropy dip angles. The MWCS at the bottom of the slope was greatly affected by the anisotropy ratios and the dip angles of the rock formation. Meanwhile, the RID was found to be less affected by the anisotropy ratios and the dip angles of the rock formation.

(4) The permeability anisotropy had a greater impact on the deformations and stability of the anti-dipping layered rock slope. Under the conditions that only the anisotropy ratios were considered, as well as under the conditions that both the anisotropy ratios and the dip angles of the formation were considered, the MHD and MSF values were quite different. Therefore, for anti-dipping layered rock slopes, both the anisotropy ratios and rock layer dip angles should be considered in deformation and stability analysis processes.

(5) The safety factors (SF) of slopes tend to be overestimated when the seepage of an anti-dipping layered slope is considered to be isotropic. With the decreases of the anisotropy ratios and the increases of the inverse tilt angles of the layered plane, the SF of the examined slope had gradually decreased. However, when the inclination of an inverted layer plane of a rock slope is large, greater protection measures were required for the slope.

\section{Data Availability}

The datasets used or analyzed during the current study are available from the corresponding author on reasonable request.

\section{Conflicts of Interest}

The authors declare that they have no conflicts of interest.

\section{Author Contributions}

498 Guangkeng Zhang wrote the manuscript, completed the experiment and method design, analyzed the data, and performed the experiments. Guangyin Lu and Chengzhi Xia helped provide analysis of raw data. Lianrong Wu and Zongming Xu helped polish the manuscript. Guangyin Lu provided research funding. Ying Bai and Jialu Li changed the format of the manuscript. All authors have read and agreed to the published version of the manuscript. 
The authors gratefully acknowledge the finances support provided by The National Natural Science Fund (grant no. 41974148).

\section{Funding}

This research was funded by the National Natural Science Foundation of China, grant number 41974148, Hunan Provincial Key Research and Development Program, grant number 2020SK2135, Science and Technology Progress and Innovation Project of Transport Department of Hunan Province, grant number 202012 and Zhejiang 2020 Transportation Science and Technology Plan Project, grant number 2020041. The APC was funded by 51041974148.

\section{$511 \quad$ References}

512 Brooks RH, Corey AT(1964) Hydrology and Water Resources Program: Fort Collins,Colo. Hydraulic Properties of Porous Media

Cheng HL, Huang C, Weng MC(2019) Failure mechanism of a mudstone slope embedded with steep anti-dip layered sandstones: case of the 2016 Yanchao catastrophic landslide in Taiwan. Landslides 40(11):2233-

Chen YF, Yu H, Ma HZ et al(2020) Inverse modeling of saturated-unsaturated flow in site-scale fractured rocks using the continuum approach: A case study at Baihetan dam site, Southwest China. J. Hydrol 584:124693-

Cheng DX, Liu DA, Ding EB et al(2005) Analysis on influential factors and toppling conditions of toppling rock slope. Chinese Journal Geotechnical Engineering 27(11):127-131

Calgary AB Canada(2010) GEO-SLOPE International Ltd. Seepage Modeling with SEEP/W 2007: 1-207

Dakshanamurthy VFDC, Rahardjo H(1987) Coupled tedmensional colidation theory of unsaturated porous media Proceedings of the Fith Intenational Conference on Expansive Soils. Adelaide 99-103

Fredlund DG, Xing AQ(1994) A structure for deoxyribose nucleic acid. Canadian Geotechnical Journal 31(4):521-532

Gan YD, Jia YW, Wang K et al(2015) Rainfall infiltration model of layered soil considering air resistance. Journal of Hydraulic Engineering 46(2):164-173 (in Chinese)

Genuchten VTM(1980) A Closed-form Equation for Predicting the Hydraulic Conductivity of Unsaturated Soils1. Soil Science Society of America Journal 44(5):892-898

Huang YL, Qian JF, Li XH et al(2019) Stability Analysis of Anti-toppling Rock Slope. Bulletin of science and technology 35(3):181-186 (in Chinese)

Iverson RM(2000) Landslide triggering by rain infiltration. Water Resources Research 36(7):1897-1910

Kulatilake PHSW, Malama B, Wang WL(2001) Physical and particle flow modeling of jointed rock block behavior under uniaxial loading. International Journal of Rock Mechanics and Mining Sciences 38(5):641657

Liu CZ, Chen HQ, Han B, Chen H(2010) Technical support system of emergency response for serious geohazards. Geological Bulletin of China 29(1):147-156 (in Chinese)

Liu X, Shen YP, Zhang P et al(2020) Deformation characteristics of anti-dip rock slope controlled by discontinuities: a case study. Bulletin of Engineering Geology and the Environment:1-11

540 Morgenstern NR, Price VE(1965) The Analysis of the Stability of General Slip Surfaces. Géotechnique 
Mualem Y(1976) A new model for predicting the hydraulic conductivity of unsaturated porous media. Water Resources Research 12(3):513-522

Ning S, Zhuang Y, Tan YZ, Dong DX(2021) Stability Analysis of Anti-slide Pile Slope Considering Soil Anisotrop. J of China Three Gorges Univ.(Natural Sciences) 43(1):43-47 (in Chinese)

Song YQ, Chao CJ, Ye GL(2018) Permeability and anisotropy of upper Shanghai clays. Rock Soil Mech 39(6):2139-2144

Su LH, Li W, Ling N(2012) Study on losing stability mechanism of flare rock slopes-A case study of the left bank slope Jingping first-stage hydropower station. Sichuan Building Science 38(1):109-144 (in Chinese)

Tao ZG, Yu YF, Shi GC, Sun YH(2020) Comprehensive Engineering Geological Analysis on Large-Scale Antidip Slopes: A Case Study of Changshanhao Opencast Gold Mine in China. Geotechnical and Geological Engineering: $1-20$

Xiao YY, Li AR(2020) Change of Soft Rock Slope Stability with Weak Interlayer under Rainfall Conditions. Journal of Yibin University 20(12):16-19 (in Chinese)

Xia CZ, Lu GY, Bai DX(2020) Sensitivity Analyses of the Seepage and Stability of Layered Rock Slope Based on the Anisotropy of Hydraulic Conductivity: A Case Study in the Pulang Region of Southwestern China. Water 12(8):2314

Yang P, Yang J(2015) Rainfall threshold surface for slopes stability considering antecedent rainfall. Rock and Soil Mechanics 36(1):169-174 (in Chinese)

Yang ZY, Chen JM, Huang TH(1998) Effect of joint sets on the strength and deformation of rock mass models. International Journal of Rock Mechanics and Mining Sciences 35(1):75-84

Yeh PT, Lee KZ, Chang KT(2020) 3D Effects of permeability and strength anisotropy on the stability of weakly cemented rock slopes subjected to rainfall infiltration. Engineering Geology 266:105459

Yu SY, Ren XH, Zhang JX(2020) Sensibility Analysis of the Hydraulic Conductivity Anisotropy on Seepage and Stability of Sandy and Clayey Slope. Water 12(1):277

Yao Y, Zhang GC, Chen HJ et al(2020) Study on the failure mechanism of rock slope with layered cataclastic structure. Chinese Journal of Rock Mechanics and Engineering 40(X):1-16 (in Chinese)

Yu SY, Ren XH, Zhang JX et al(2020) Seepage, Deformation and Stability Analysis of Sandy and Clay Slopes with Different Permeability Anisotropy Characteristics Affected by Reservoir Water Level Fluctuations. Water 12(1):201

Zhong DH, An N, Li MC(2007) 3D dynamic simulation and analysis of slope instability of reservoir banks. Chinese Journal of Rock Mechanics and Engineering 26(2):360-367 (in Chinese)

Zhang GR, Yin KL, Liu LL et al(2005) A real-time regional geological hazard warning system in terms of WEBGIS and rainfall. Rock and Soid Mechanics 26(8):1312-1317 (in Chinese)

Zhang J, Han TC, Dou HQ, Ma SG(2014) Stability of loess slope considering infiltration zonation. Journal of Central South University (Science and Technology) 45(12):4355-4361 (in Chinese)

Zhou WH, Yang YY(1990) A structure for deoxyribose nucleic acid. Journal of Hydraulic Engineering 46(11):48-54 (in Chinese)

Zhu WS, Zhang G(1994) Sensitivity analysis of the influence of jointed rock mass parameters on surrounding rock damage zone. Underground Space 14(1):10-15 (in Chinese) 
581 Zhu C, He CM, Karakus M(2020) Investigating Toppling Failure Mechanism of Anti-dip Layered Slope due to 
Figures

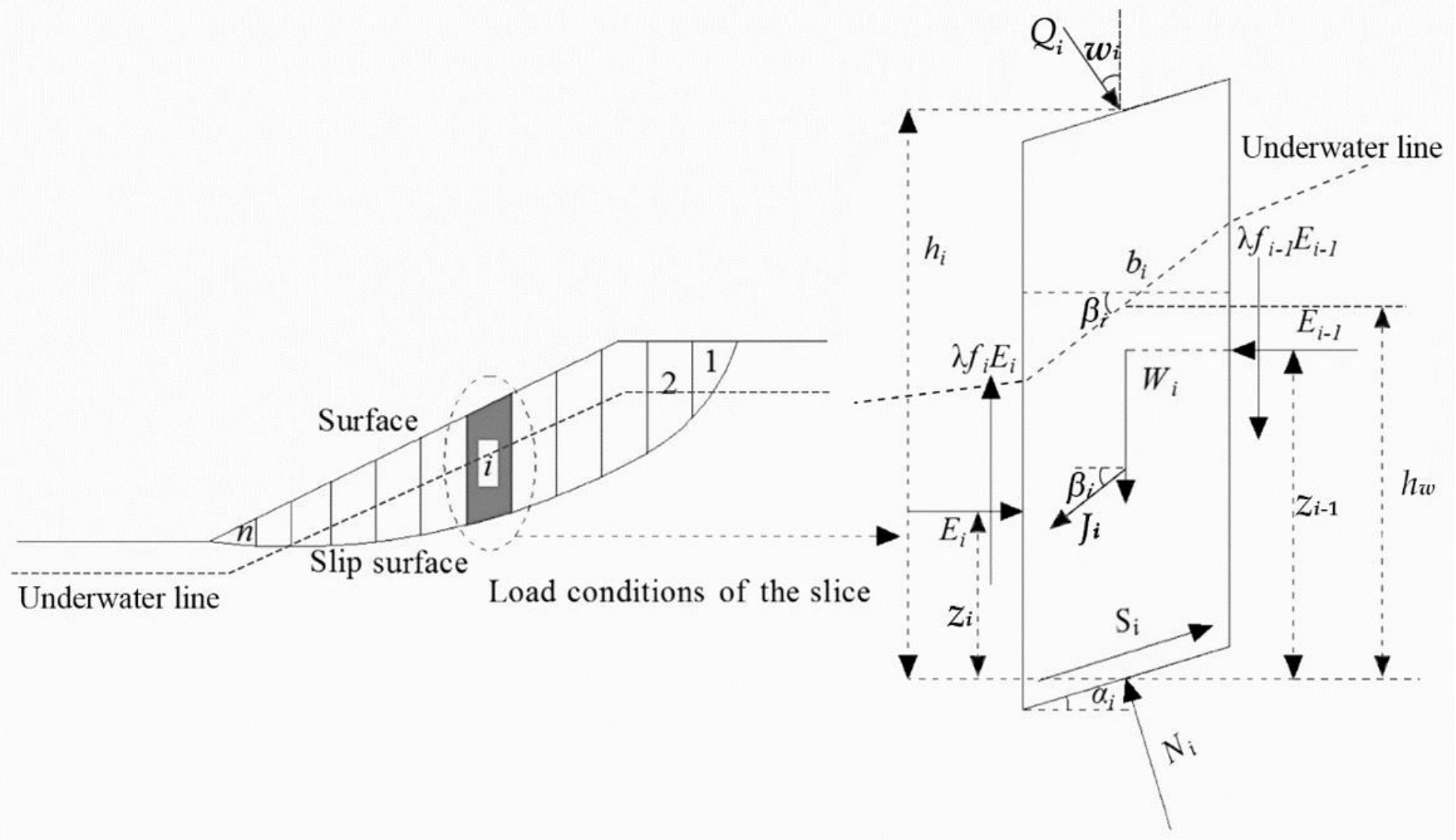

\section{Figure 1}

Calculation principle and model of the Morgenstern-Price $(M-P)$ Method 


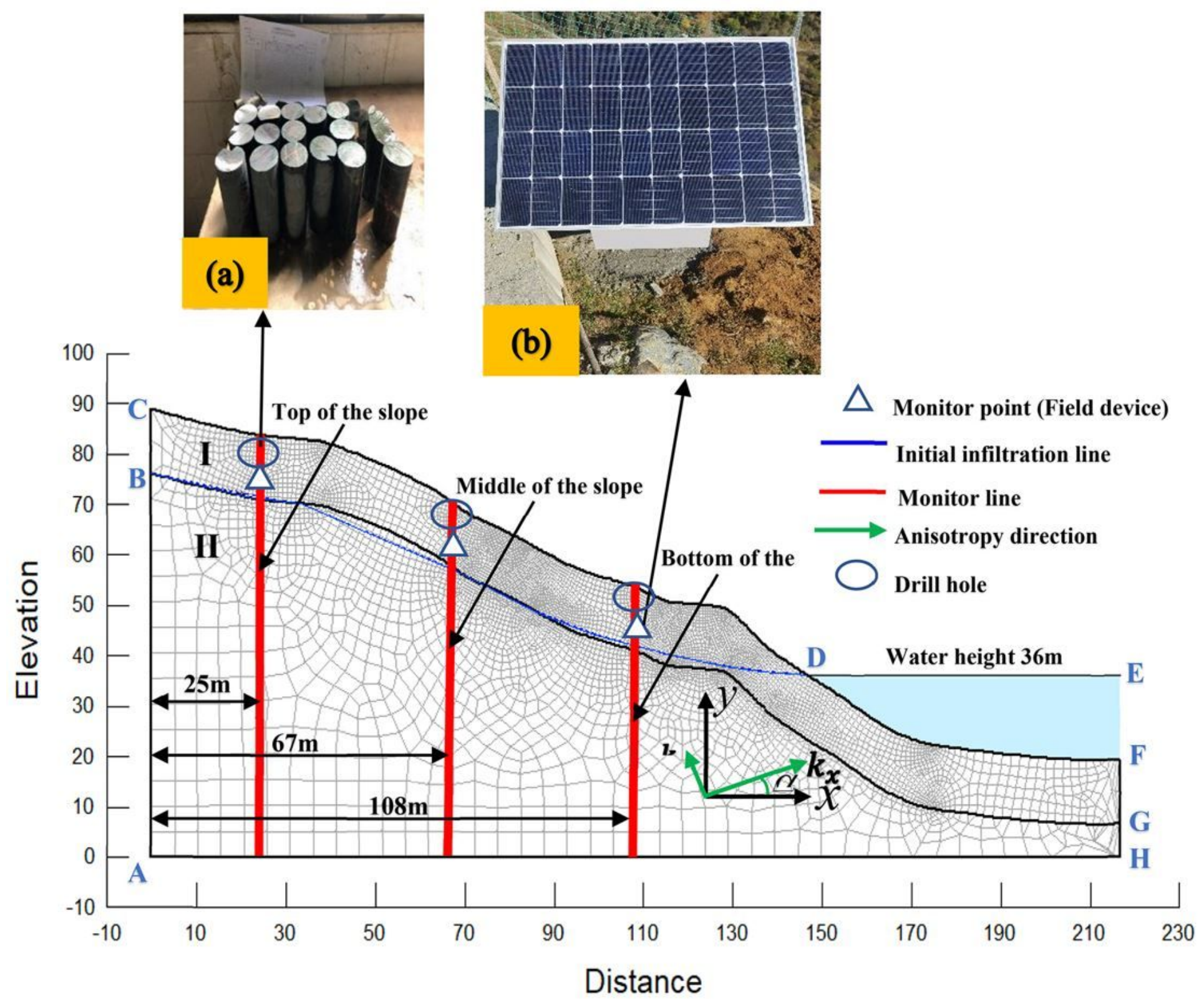

Figure 2

Grid model 


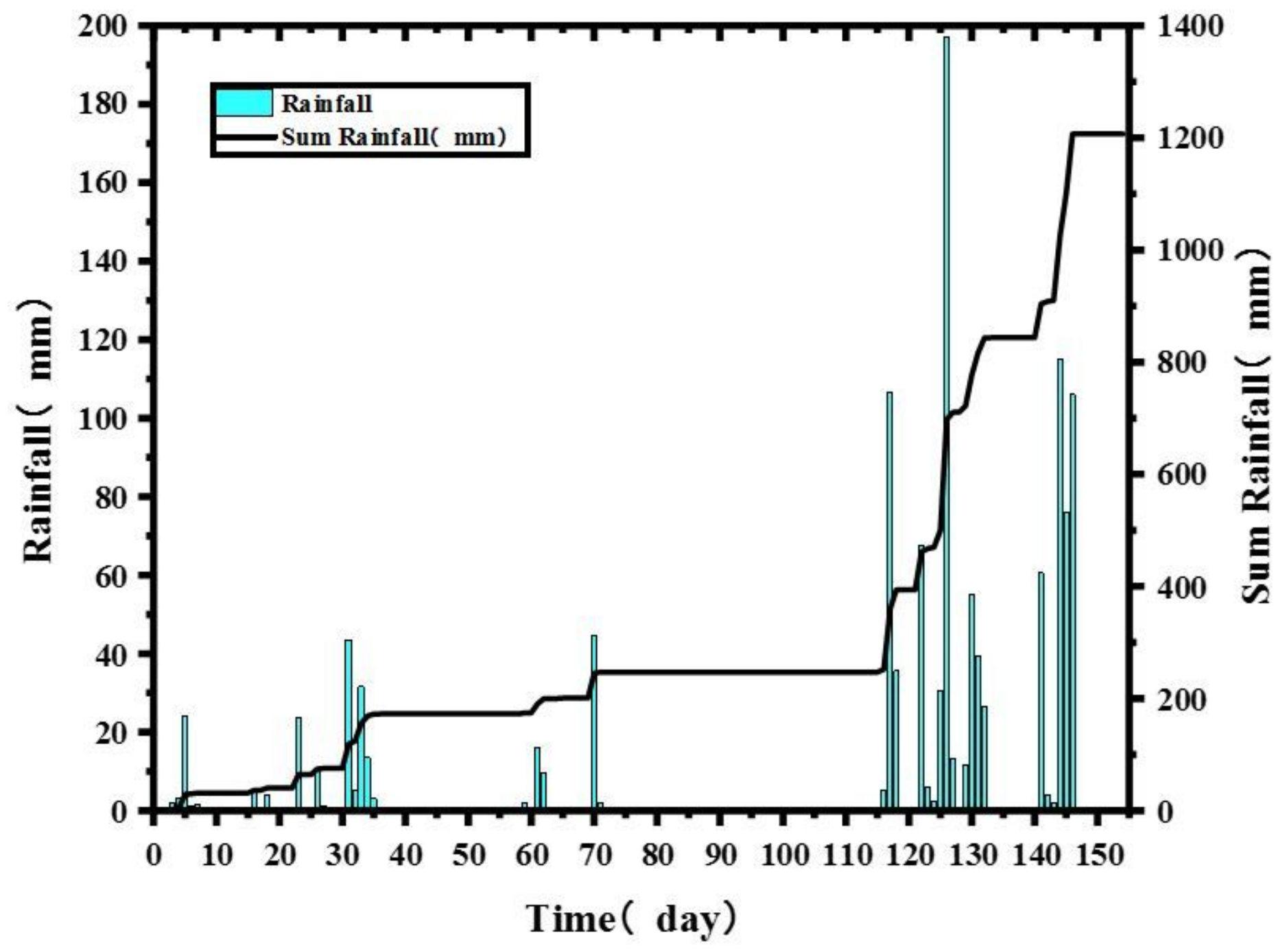

Figure 3

Daily rainfall values from March 1st to August 1st of 2019 


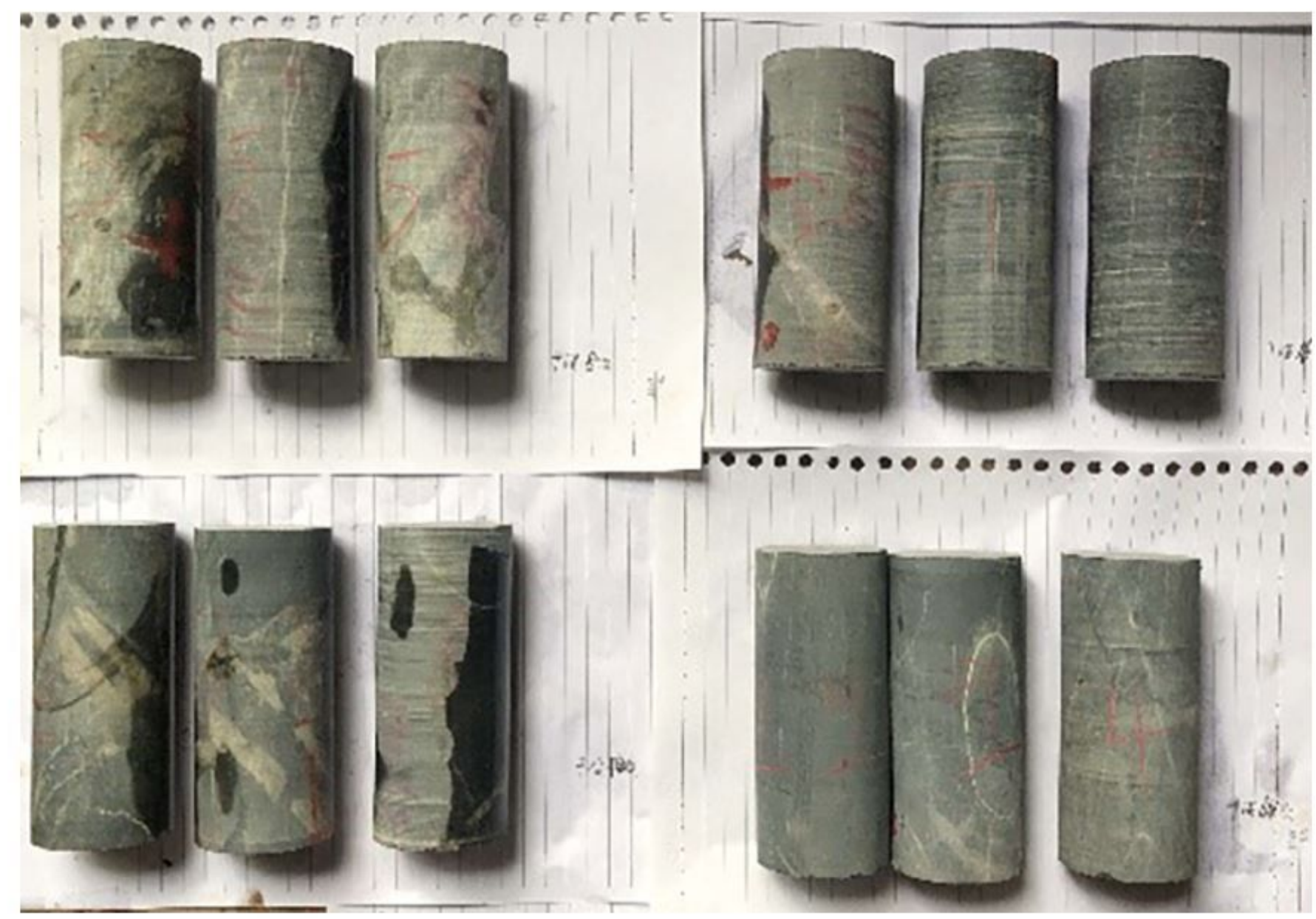

\section{Figure 4}

Images of the carbonaceous slate samples
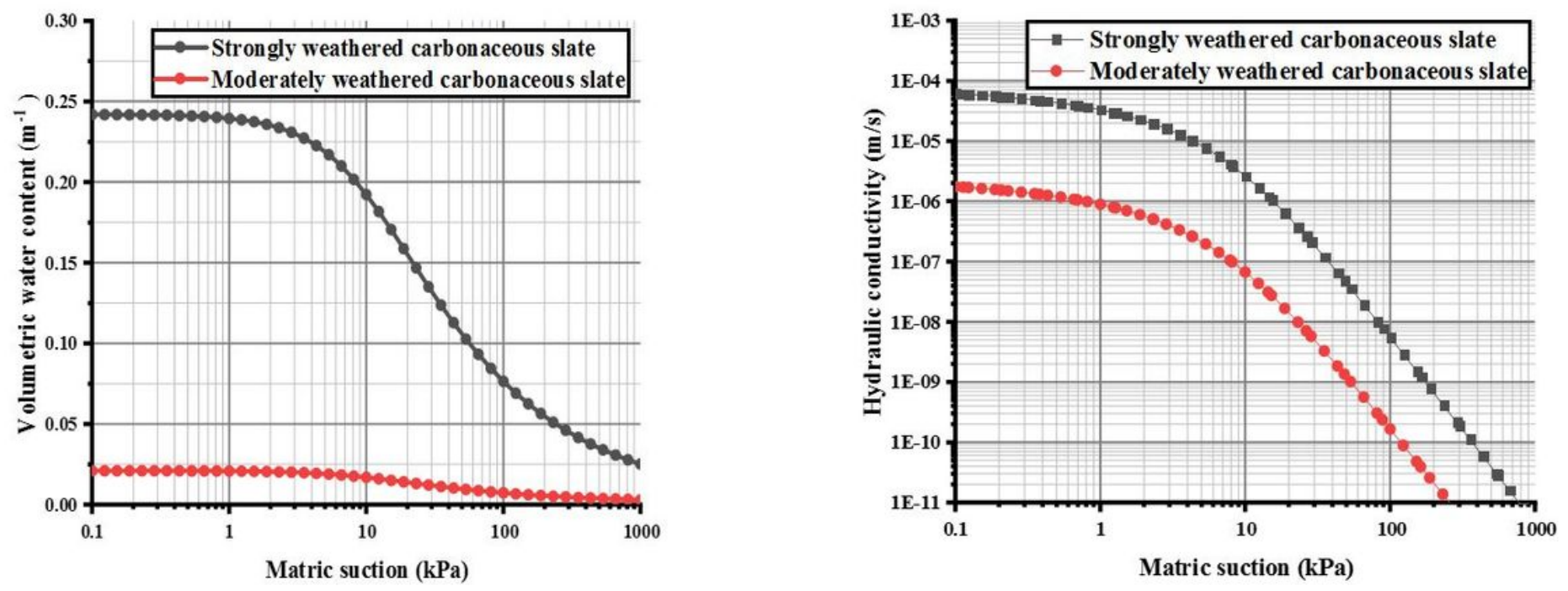

(a)

(b) 


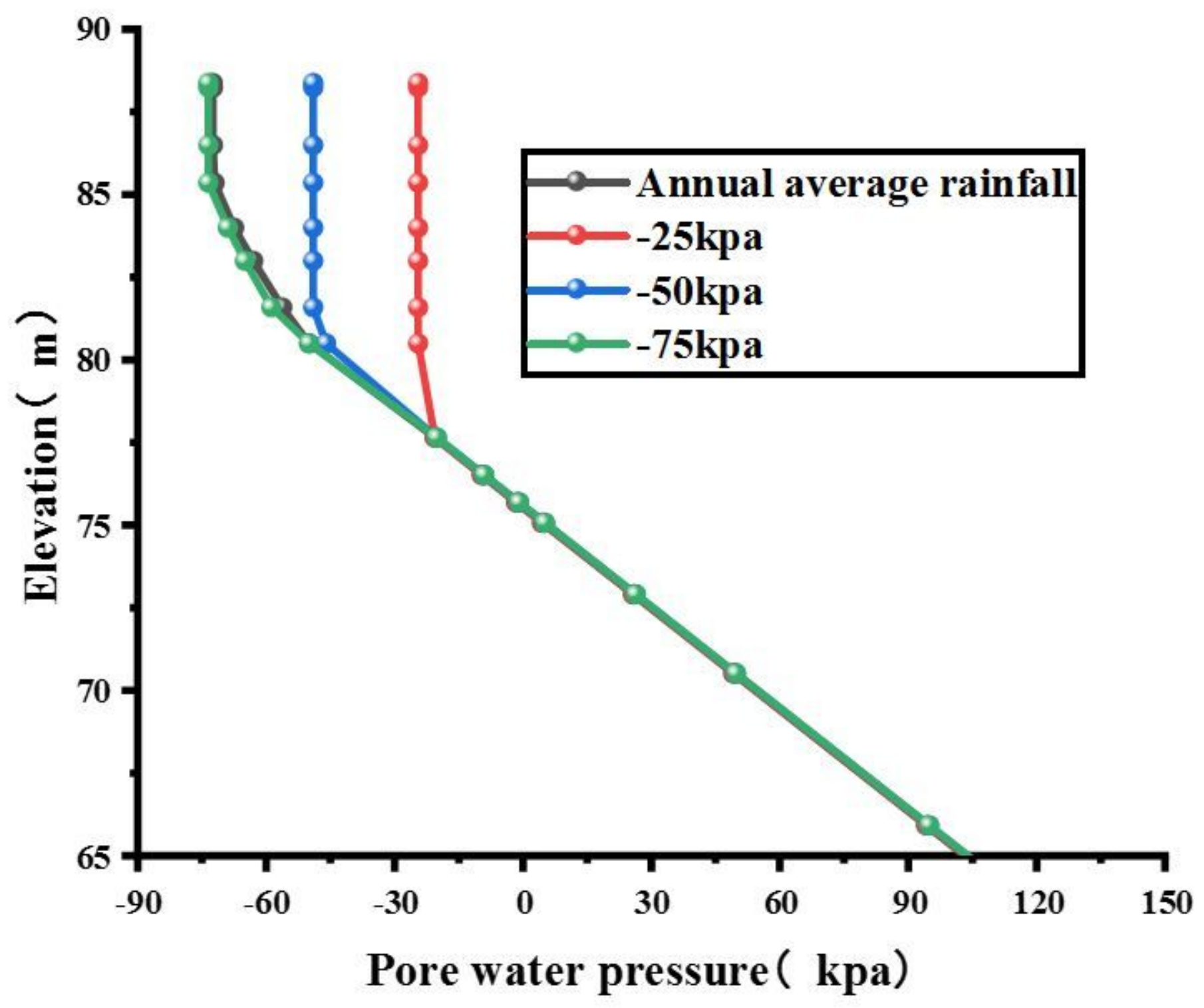

Figure 6

Initial pore pressure distribution 


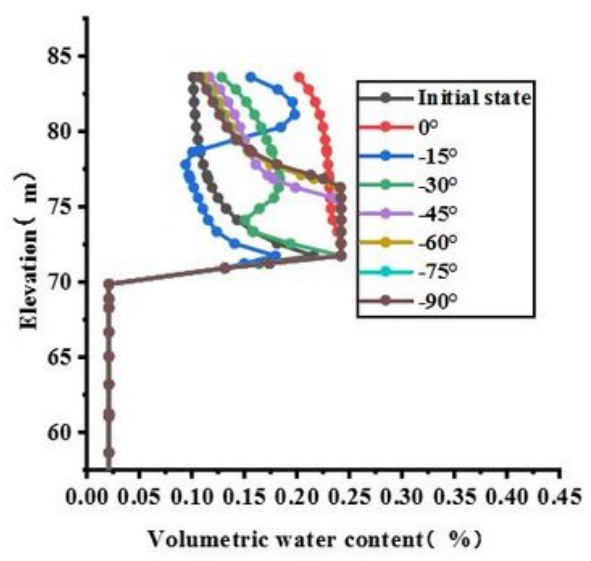

(a)

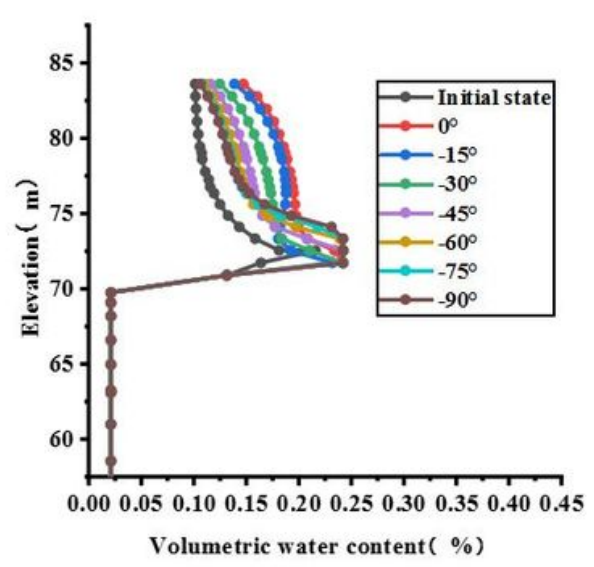

(d)

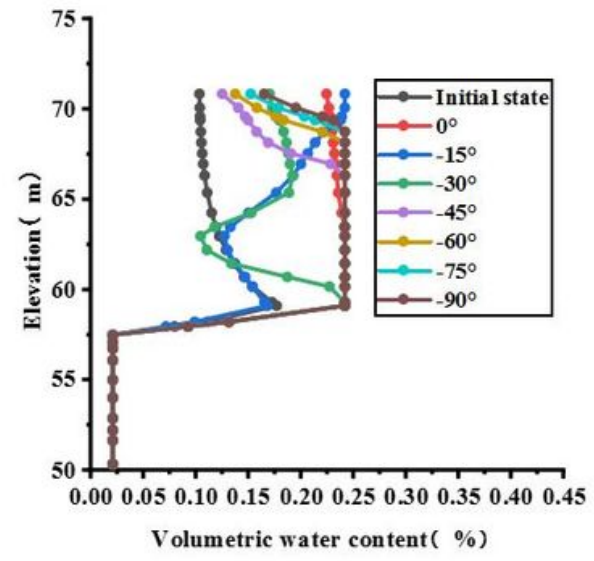

(b)

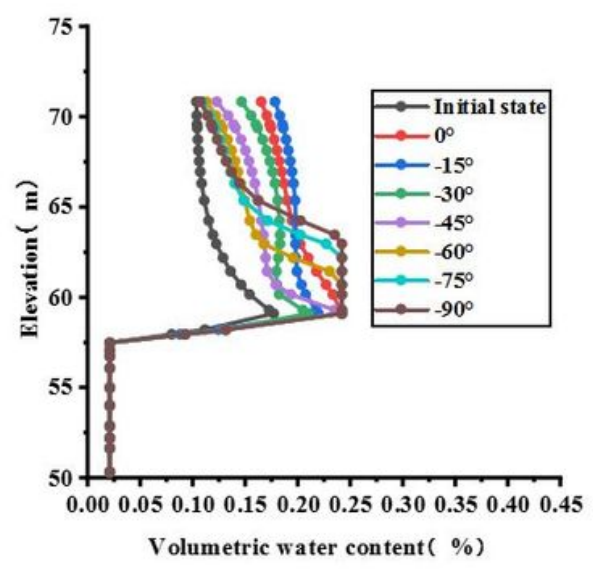

(e)

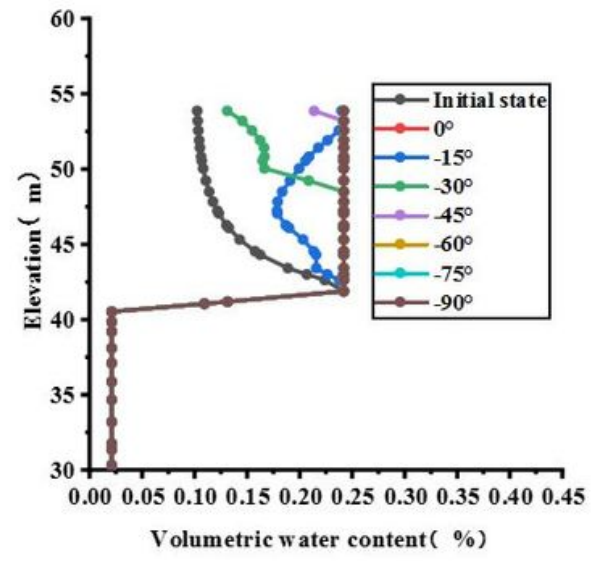

(c)

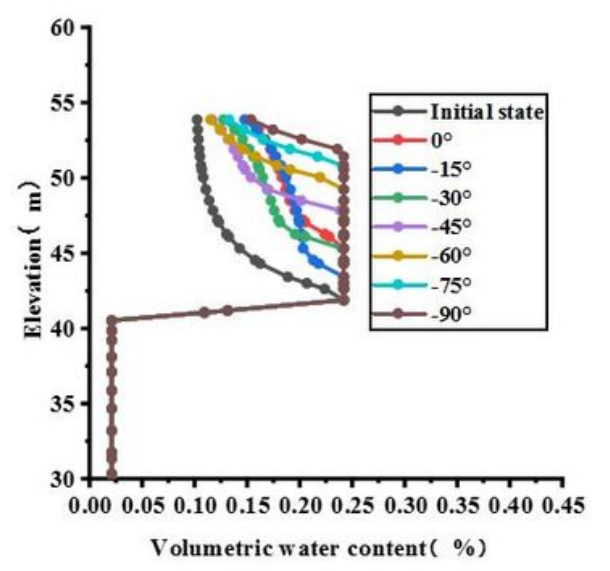

(f)

\section{Figure 7}

Variations in the volumetric water content levels under different a values for the anti-dipping carbonaceous slate slopes: a Top of the slope with $\mathrm{kr}=0.01, \mathrm{~b}$ Middle of the slope with $\mathrm{kr}=0.01, \mathrm{c}$ Bottom of the slope with $k r=0.01, d$ Top of the slope with $k r=0.1$, e Middle of the slope with $k r=0.1$, $f$ Bottom of the slope with $\mathrm{kr}=0.1$ 


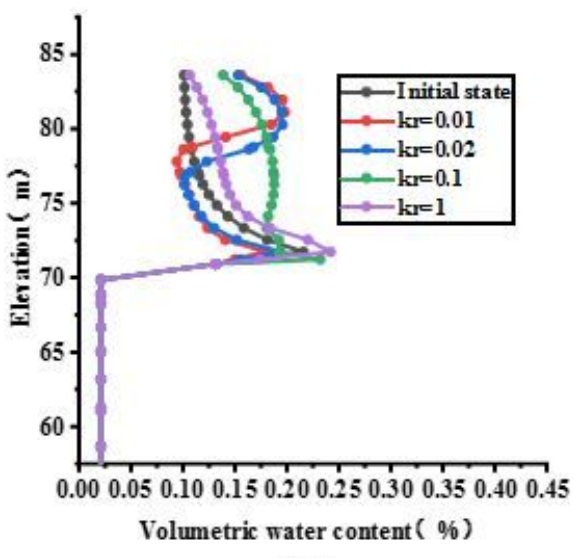

(a)

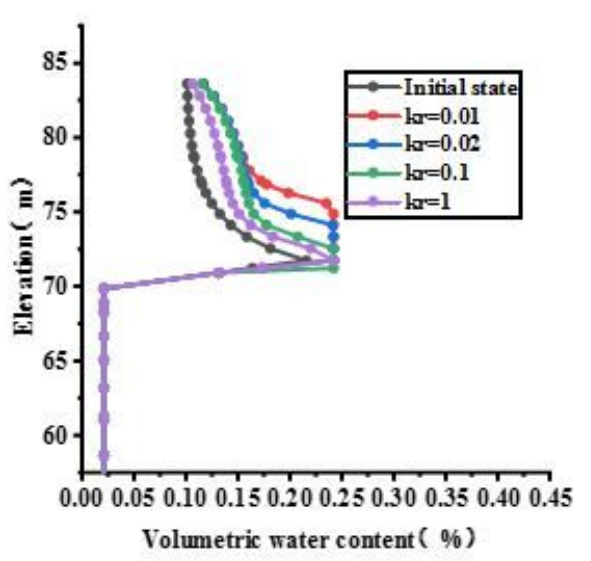

(d)

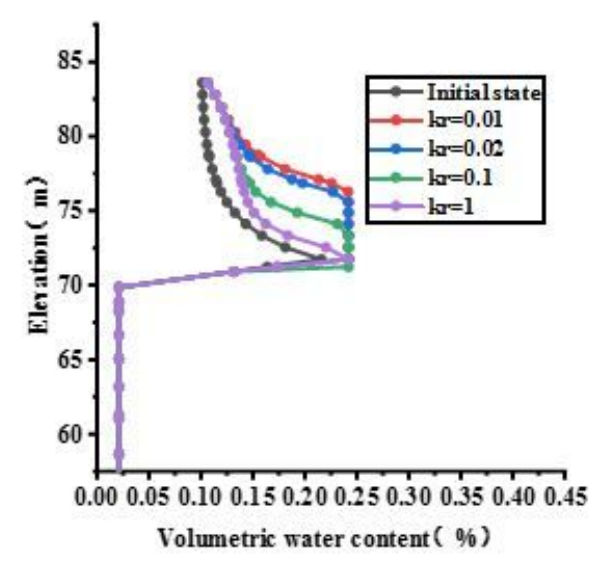

(g)

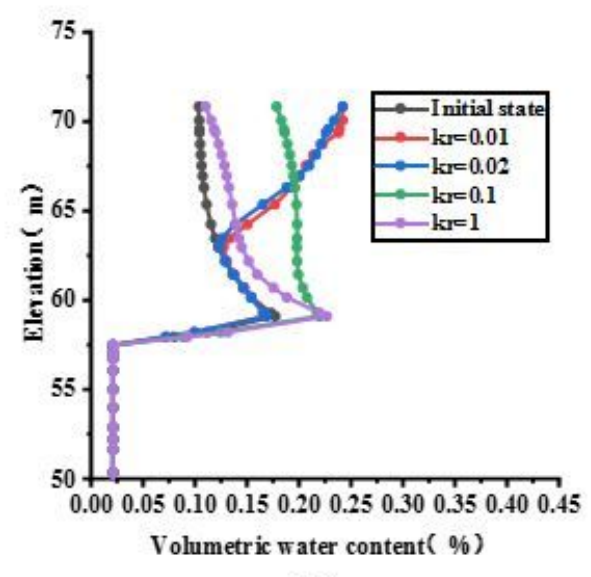

(b)

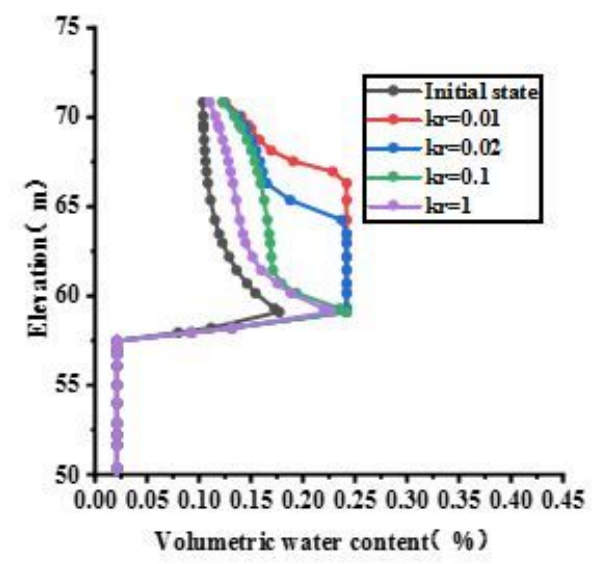

(e)

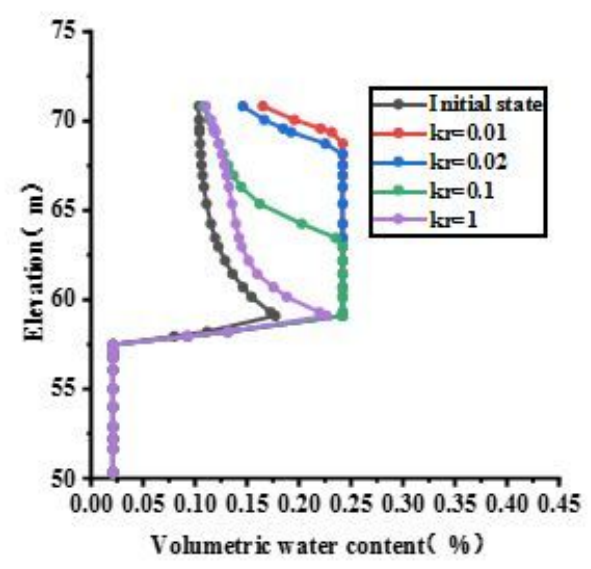

(h)

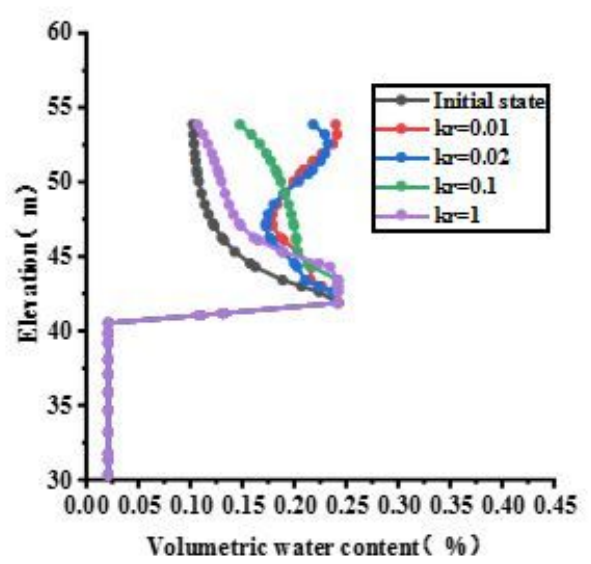

(c)

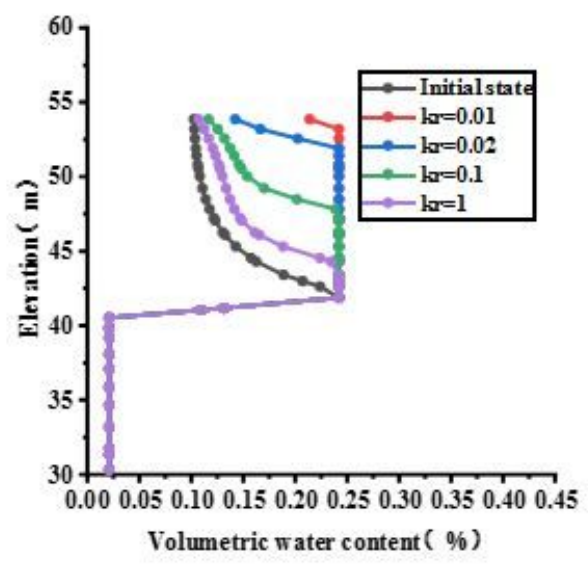

(f)

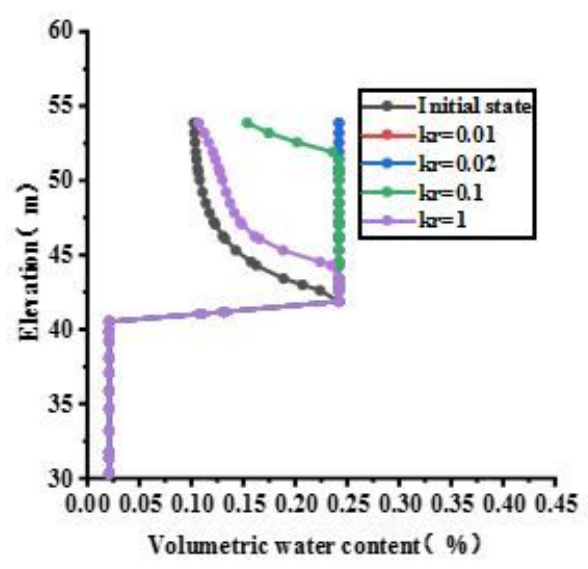

(i)

\section{Figure 8}

Volumetric water content levels at different positions on the anti-dipping carbonaceous slate slope under different kr values with $a=-15^{\circ} \square a=-30^{\circ}$ and $a=-45^{\circ}$ : a Top of the slope with $a=-15^{\circ}$, $b$ Middle of the slope with $a=-15^{\circ}, c$ Bottom of the slope with $a=-15^{\circ}, d$ Top of the slope with $a=-45^{\circ}$, e Middle of the slope with $a=-45^{\circ}, f$ Bottom of the slope with $a=-45^{\circ}, g$ Top of the slope with $a=-90^{\circ}$, h Middle of the slope with $a=-90^{\circ}$, i Bottom of the slope with $a=-90^{\circ}$. 


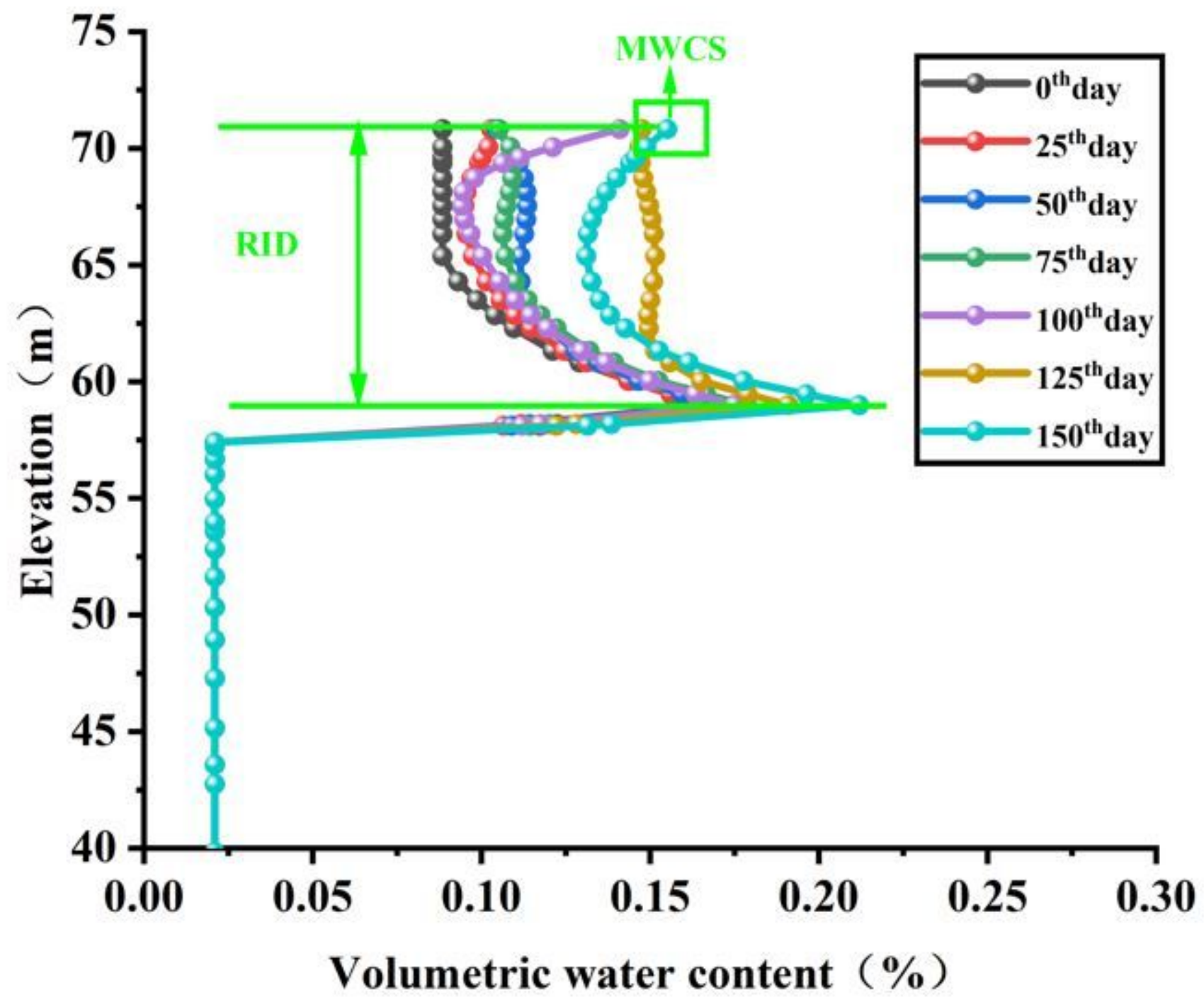

Figure 9

Variations in the volumetric water content levels 


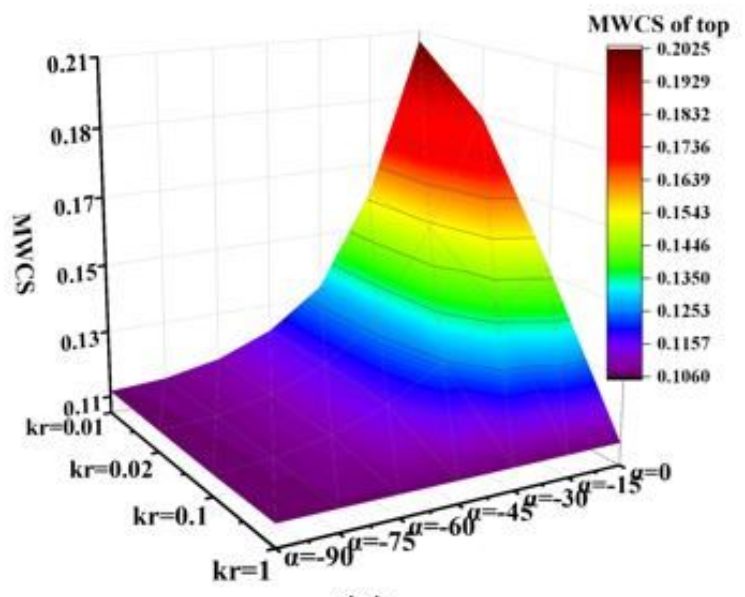

(a)

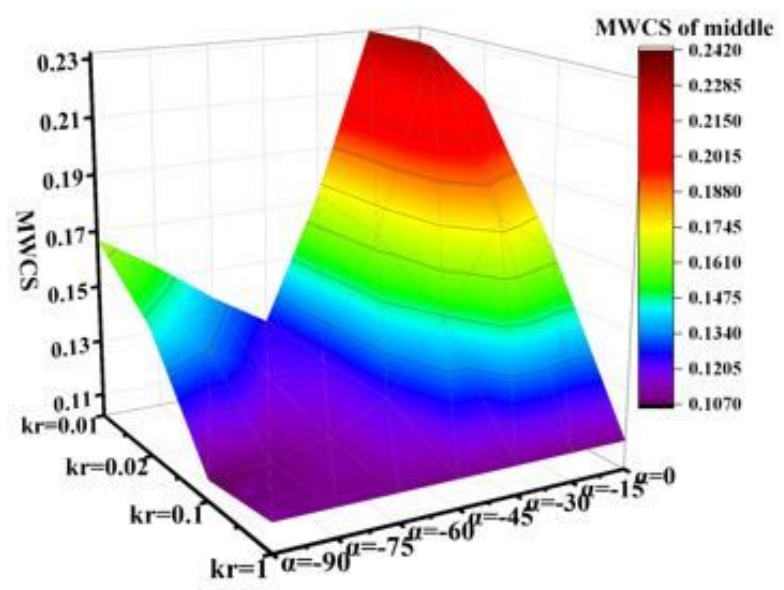

(b)

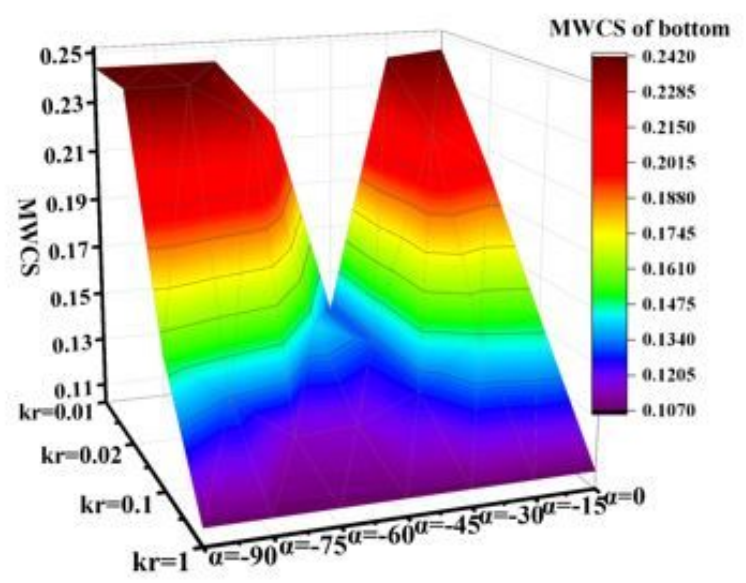

(c)

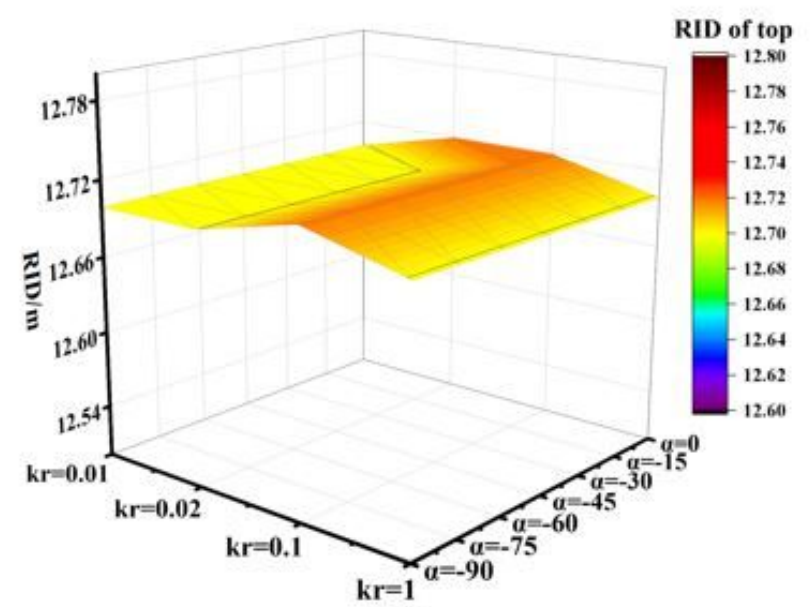

(d)

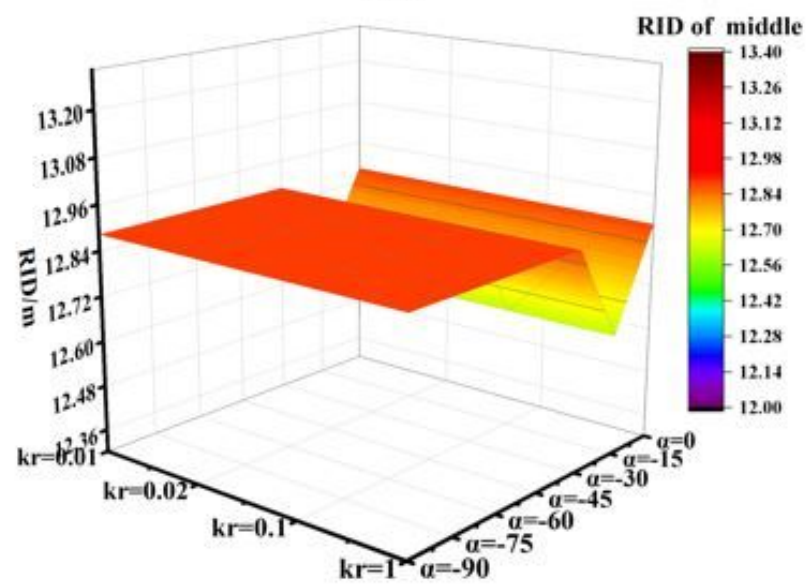

(e)

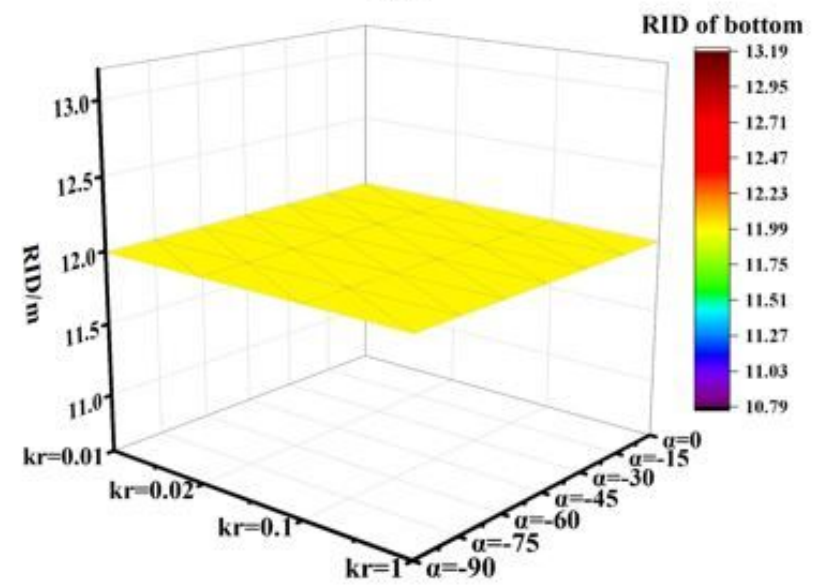

(f)

\section{Figure 10}

Variations in the MWCS and RID with different kr and $a$ : a MWCS of top of the slope, b MWCS of the middle of the slope, c MWCS of the bottom of the slope, d RID of top of the slope, e RID of middle of the slope, $f$ RID of the bottom of the slope. 


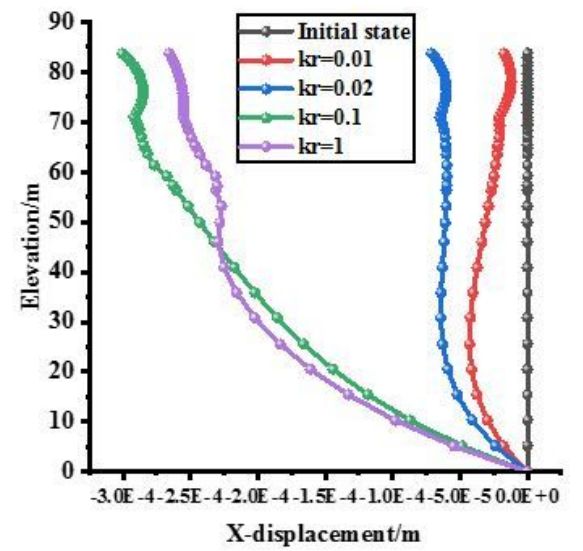

(a)

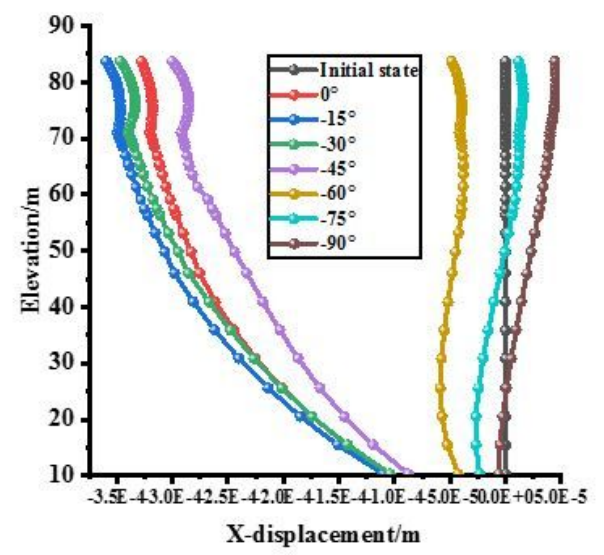

(d)

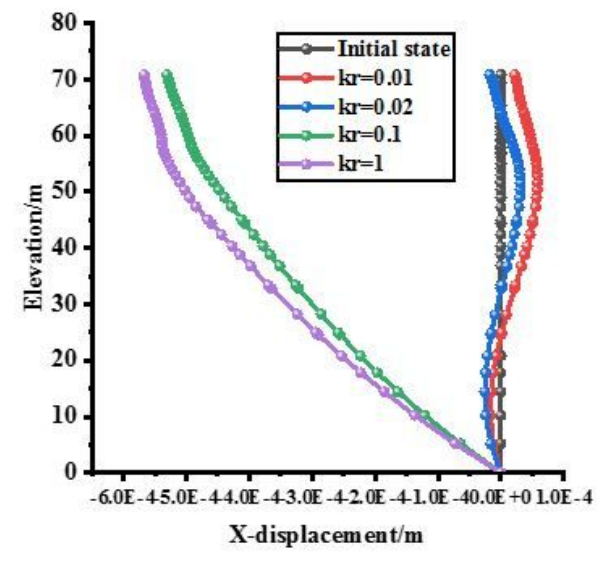

(b)

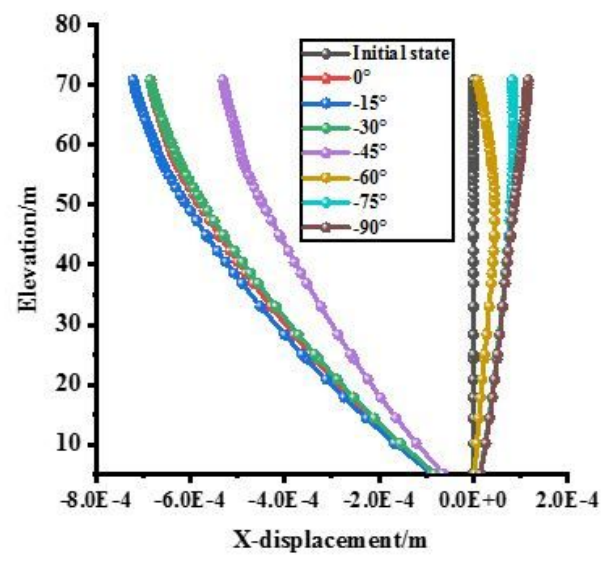

(e)

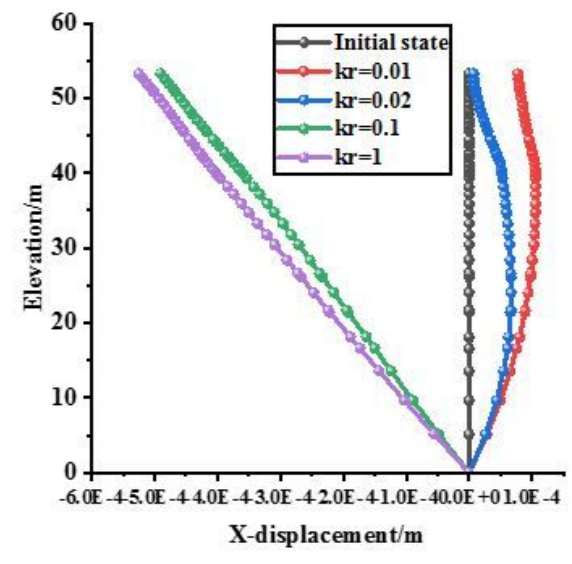

(c)

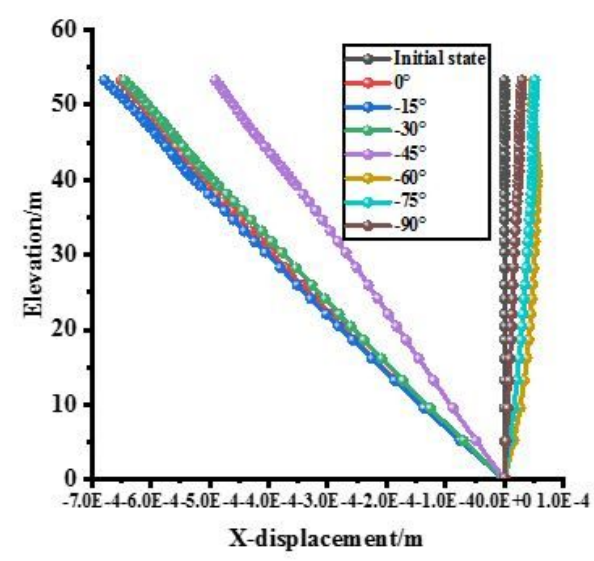

(f)

\section{Figure 11}

Variations in the $\mathrm{x}$-displacement under different $\mathrm{kr}$ and a values for anti-dipping carbonaceous slate slopes: a Top of the slope with $a=-45^{\circ}, b$ Middle of the slope with $a=-45^{\circ}, c$ Bottom of the slope with $a=$ $-45^{\circ}$, $d$ Top of the slope with $k r=0.1$, e Middle of the slope with $k r=0.1, f$ Bottom of the slope with $k r=0.1$

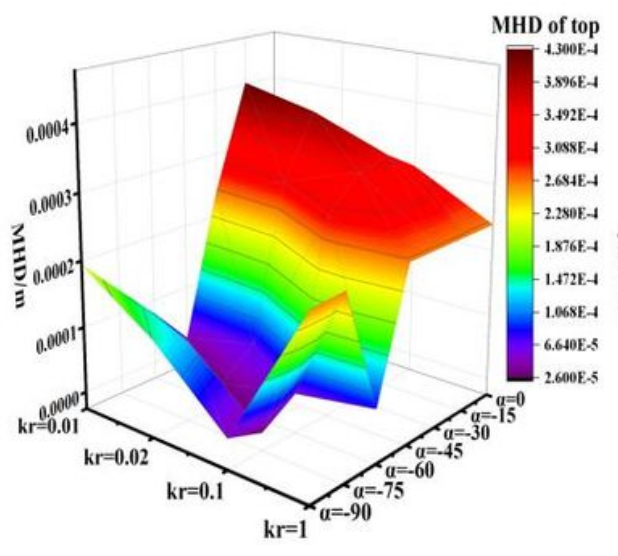

(a)

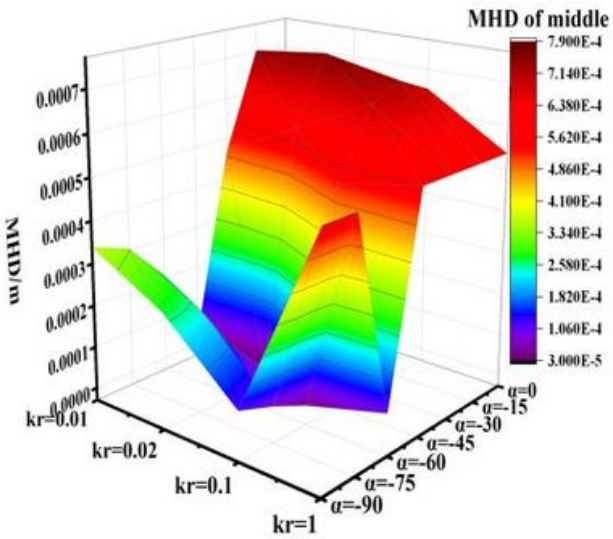

(b)

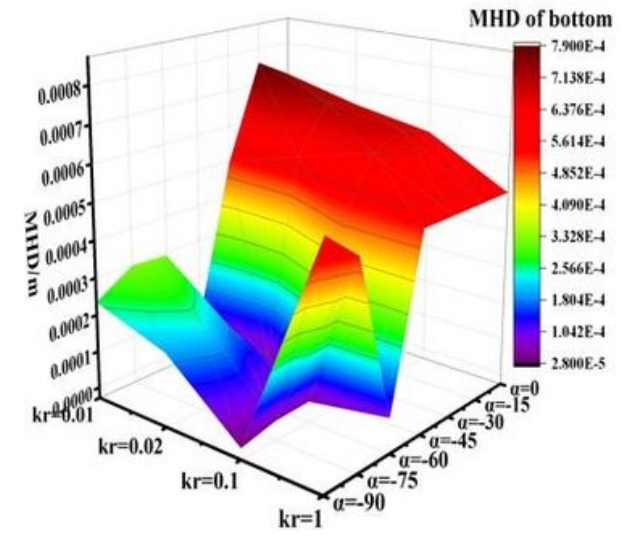

(c) 
Variations in the maximum horizontal displacement (MHD) under different $k r$ and a values: a Top of the slope, $b$ Middle of the slope, c Bottom of the slope

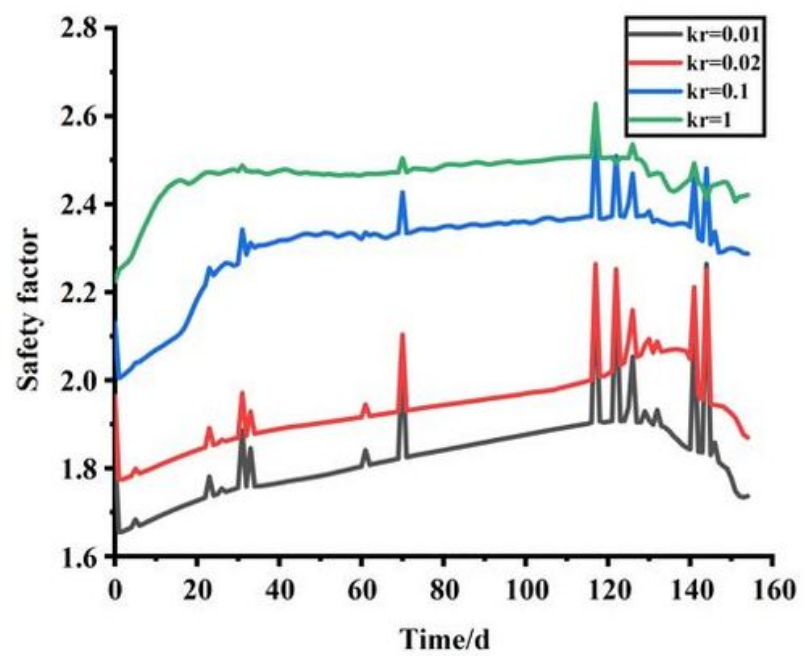

(a)

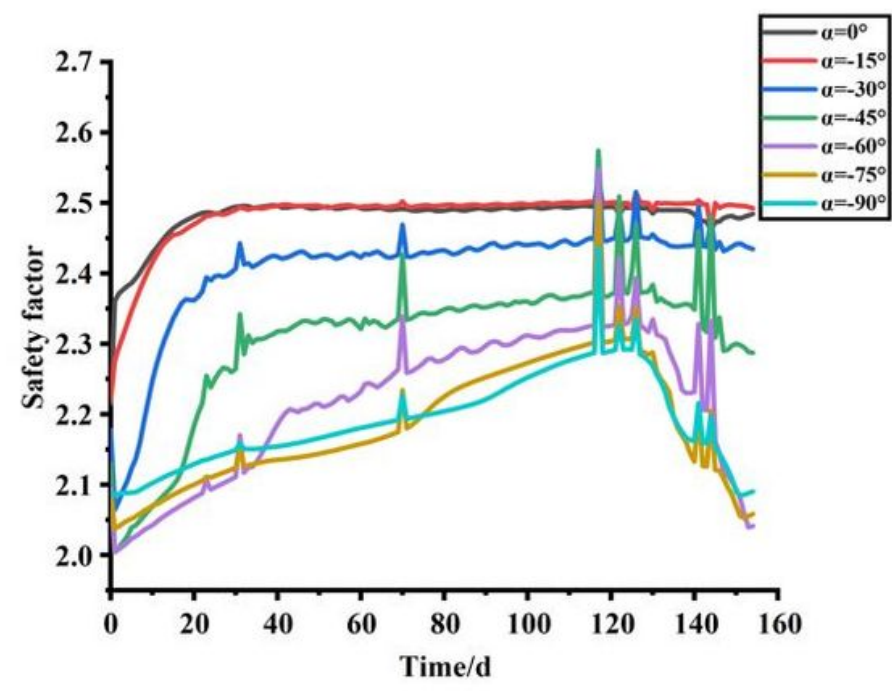

(b)

Figure 13

Variations in the safety factors under different $\mathrm{kr}$ and a values for anti-dipping carbonaceous slate slope: a Slope with $\mathrm{a}=-45^{\circ}$, $\mathrm{b}$ Slope with $\mathrm{kr}=0.1$ 


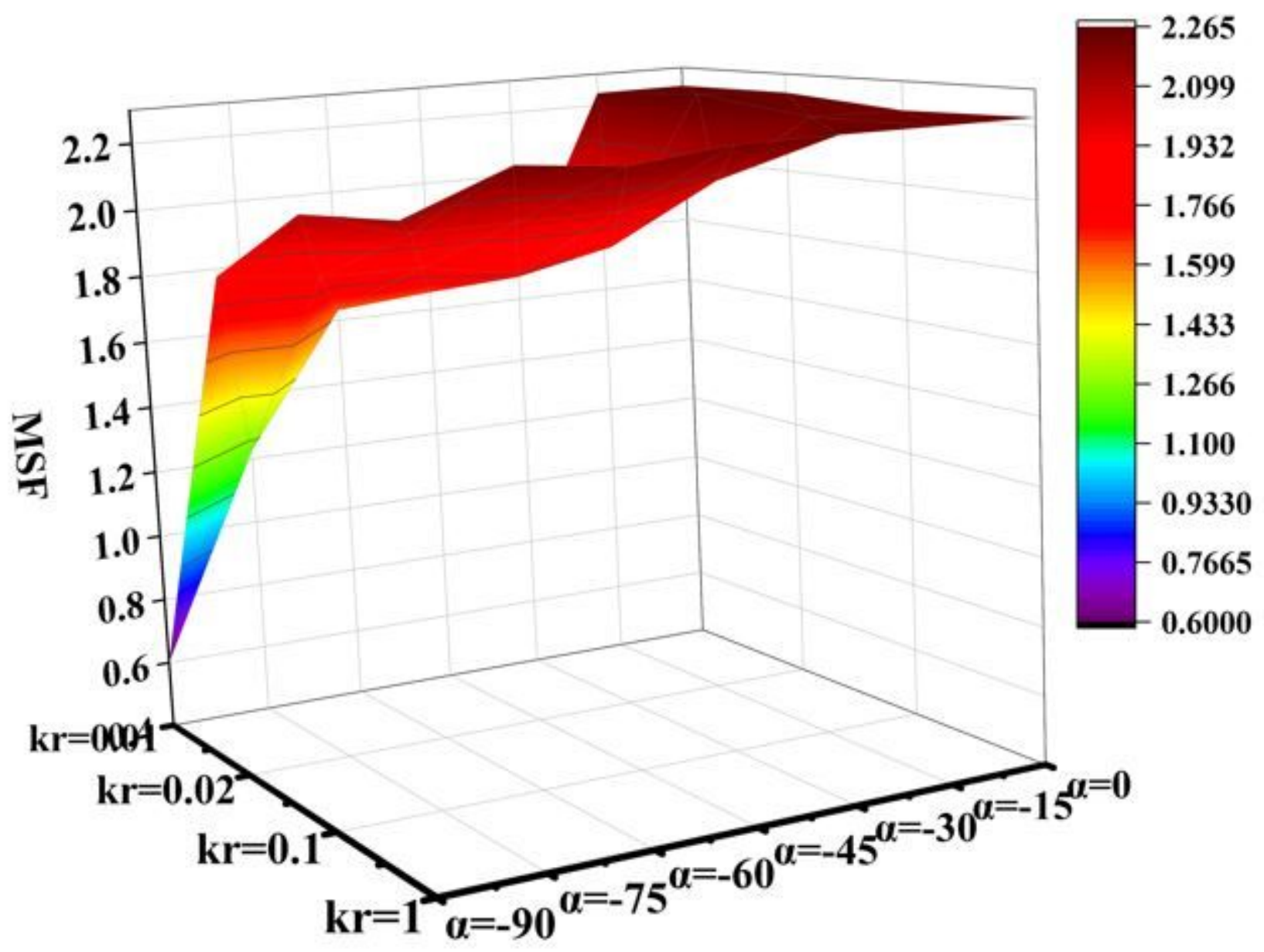

Figure 14

Variations in the SF for anti-dipping carbonaceous slate slopes 